\title{
Tomato Whole Genome Transcriptional Response to Tetranychus urticae Identifies Divergence of Spider Mite-Induced Responses Between Tomato and Arabidopsis
}

\author{
Catherine Martel, ${ }^{1}$ Vladimir Zhurov, ${ }^{1}$ Marie Navarro, ${ }^{1,2}$ Manuel Martinez, ${ }^{3}$ Marc Cazaux, ${ }^{1,2}$ Philippe Auger, ${ }^{4}$ \\ Alain Migeon, ${ }^{4}$ M. Estrella Santamaria, ${ }^{1,3}$ Nicky Wybouw, ${ }^{5}$ Isabel Diaz, ${ }^{3}$ Thomas Van Leeuwen, ${ }^{5,6}$ \\ Maria Navajas, ${ }^{4}$ Miodrag Grbic, ${ }^{1,2}$ and Vojislava Grbic ${ }^{1,2}$ \\ ${ }^{1}$ Department of Biology, The University of Western Ontario, London, ON, Canada N6A5B7; ${ }^{2}$ Instituto de Ciencias de la Vid y \\ el Vino, 26006 Logrono, Spain; ${ }^{3}$ Centro de Biotecnologia y Genomica de Plantas, Universidad Politécnica de Madrid- \\ Instituto Nacional de Investigación y Tecnología Agraria y Alimentaria, 28223 Madrid, Spain; ${ }^{4}$ INRA, UMR CBGP \\ (INRA/IRD/Cirad/Montpellier SupAgro), 34998 Montferrier-sur-Lez Cedex, France; ${ }^{5}$ Department of Crop Protection, Ghent \\ University, B-9000, Ghent, Belgium; ${ }^{6}$ Institute for Biodiversity and Ecosystem Dynamics, University of Amsterdam, 1098 XH, \\ Amsterdam, The Netherlands
}

Submitted 30 September 2014. Accepted 22 December 2014.

The two-spotted spider mite Tetranychus urticae is one of the most significant mite pests in agriculture, feeding on more than 1,100 plant hosts, including model plants Arabidopsis thaliana and tomato, Solanum lycopersicum. Here, we describe timecourse tomato transcriptional responses to spider mite feeding and compare them with Arabidopsis in order to determine conserved and divergent defense responses to this pest. To refine the involvement of jasmonic acid (JA) in mite-induced responses and to improve tomato Gene Ontology annotations, we analyzed transcriptional changes in the tomato JA-signaling mutant defenseless 1 (def-1) upon JA treatment and spider mite herbivory. Overlay of differentially expressed genes (DEG) identified in def-1 onto those from the timecourse experiment established that JA controls expression of the majority of genes differentially regulated by herbivory. Comparison of defense responses between tomato and Arabidopsis highlighted 96 orthologous genes (of 2,133 DEG) that were recruited for defense against spider mites in both species. These genes, involved in biosynthesis of JA, phenylpropanoids, flavonoids, and terpenoids, represent the conserved core of induced defenses. The remaining tomato DEG support the establishment of tomato-specific defenses, indicating profound divergence of spider mite-induced responses between tomato and Arabidopsis.

Plants and herbivores have co-evolved over millions of years, resulting in a myriad of plant-herbivore interactions. Herbivores

Transcript profiling data from this article are deposited at Gene Expression Omnibus (GEO) platform GPL16358 as GEO superseries GSE61076.

Catherine Martel and Vladimir Zhurov contributed equally to the paper.

Corresponding author: V. Grbic; E-mail: vgrbic@uwo.ca

* The $\boldsymbol{e}$-Xtra logo stands for "electronic extra" and indicates that 11 supplementary datasets, five supplementary figures, and two supplementary tables are published online.

(C) 2015 The American Phytopathological Society have evolved various levels of specialization to their hosts and differ in types of feeding damage they cause, while plants range in their ability to restrict herbivore performance, contributing to the diversity and complexity of plant-herbivore interactions. Generally, plants employ two lines of defenses, constitutive and inducible, to deter herbivory. Constitutive defenses, such as trichomes and the presence of certain toxins, are a primary line of protection against a broad spectrum of potential attackers (Howe and Jander 2008). However, the lack of specificity and high energy cost of constitutive defenses are believed to have led to the evolution of inducible defenses that are triggered in response to the detection of a specific attacker (e.g., pathogen, fungus, herbivore) (Schwachtje and Baldwin 2008; Steppuhn et al. 2008). Inducible defenses against herbivores include the synthesis of a wide range of species-specific toxic plant secondary metabolites (e.g., phenylpropanoids, flavonoids, anthocyanins, alkaloids, terpenoids, glucosinolates), and anti-nutritive enzymes and proteins (e.g., proteinase inhibitors, amino acid catabolizing enzymes, polyphenol oxidases, and peroxidases) (Campos et al. 2014; Howe and Jander 2008; Mithofer and Boland 2012; Santamaria et al. 2013). In addition to these direct inducible defenses, plants also emit complex cocktails of volatiles that attract predators of herbivores as indirect defense responses (Clavijo McCormick et al. 2012; Mithofer and Boland 2012). Despite the diversity of plant-herbivore interactions, jasmonic acid (JA) has been identified as the major regulator of plant defense responses to herbivory (Campos et al. 2014).

The two-spotted spider mite Tetranychus urticae is a piercingsucking herbivore that can feed on more than 1,100 plant species (Migeon and Dorkeld 2006-2014). In the last several years, $T$. urticae has become a model chelicerate herbivore, with its genome sequenced (Grbic et al. 2011) and a number of tools and protocols for genomic and genetic studies developed (Dearden et al. 2002; Dermauw et al. 2013; Khila and Grbic 2007; Grbic et al. 2007, 2011; Van Leeuwen et al. 2012, 2013). Taking advantage of these tools, we previously reported the reciprocal whole-genome responses between Arabidopsis thaliana and T. urticae. This study highlighted JA as a key regulator and JA-dependent biosynthesis of indole glucosinolates as 
the main functional output of the Arabidopsis defenses induced by spider mite feeding (Zhurov et al. 2014). To understand the evolution and diversity of plant-herbivore interactions, we have expanded our analysis of plant-spider mite interactions to include tomato (Solanum lycopersicum) as a complementary system to study defense responses induced by spider mite feeding.

Spider mites are an economically important pest of cultivated tomatoes (Jeppson et al. 1975; Zhang 2003). Several studies of tomato-spider mite interactions highlighted the importance of constitutive defenses, such as chemical content and density of glandular trichomes, in defense against spider mites in wild tomato relatives (Glas et al. 2012). For example, acylsugars, present in trichomes of Solanum pennellii (Blauth et al. 1998; Mirnezhad et al. 2010; Mutschler et al. 1996; Resende et al. 2002; Salinas et al. 2013), methyl ketones from Solanum hirsutum (Antonious et al. 2014), and terpenoids from Solanum habrochaites (Bleeker et al. 2012) confer high levels of resistance against spider mites. Studies of induced tomato defenses to spider-mite herbivory identified the importance of JA and suggested roles for salicylic acid (SA) and ethylene (ET) in the regulation of tomato induced defenses (Ament et al. 2004; Kant et al. 2004; Li et al. 2002a; Li et al. 2004). Expression levels of the JA biosynthetic enzymes lipoxygenase D (LOXD) and allene oxide synthase 1 (AOS1), proteinase inhibitors (PI), leucine amino peptidase (LAP), threonine deaminase (TD), and polyphenol oxidases ( $P P O$ ) have been identified as highly reproducible markers of JA-dependent induced defense responses in tomato, pointing to the importance of defense proteins that reduce the quality of the plant diet or the activity of digestive enzymes in the herbivore gut (Chen et al. 2005; Chung and Felton 2011; Fowler et al. 2009; Gatehouse 2011; Gonzales-Vigil et al. 2011; Green and Ryan 1972; Kessler and Baldwin 2002; Zhu-Salzman et al. 2008). Other well-characterized tomato induced defenses include emission of volatiles, such as TMTT (E,E-4,8,12-trimethyl-1,3,7,11-tridecatetraene) and MeSA (methyl salicylate) (Kant et al. 2004, 2008), that play an important role in the attraction of the spider mite predator Phytoseiulus persimilis (Ament et al. 2004; Dicke et al. 1998). Despite being useful markers of herbivory, expression of these marker genes fails to provide a comprehensive understanding of tomato defense response to spider mite.

The completion of tomato genome sequencing (Sato et al. 2012) enables a genome-wide analysis of induced tomato transcriptome responses upon spider mite herbivory. We employed the newly developed EUTOM3 whole genome exon array to monitor early transcriptional changes occurring in tomato leaves in the first $24 \mathrm{~h}$ following spider mite attack and have compared them with defense responses triggered by spider mite feeding on Arabidopsis.

\section{RESULTS AND DISCUSSION}

\section{Tomato response to spider mite feeding.}

Induced transcriptional responses of tomato upon spider mite feeding. In order to understand genome-wide tomato transcriptional responses to spider mite herbivory, a microarray study was designed to capture early changes in gene expression following T. urticae attack in timecourse and feeding-site scenarios. We used reference tomato and mite strains whose genomes were sequenced as representatives of their species, 'Heinz 1706' tomato variety and a London strain of T. urticae (maintained on beans and, thus, nonadapted to tomato). In the timecourse experiment, the terminal leaflet of the third leaf of three-week-old tomato plants was infested with 100 adult female spider mites and tissue was collected at $0,1,3,6,12$, and $24 \mathrm{~h}$ postinfestation (hpi), while, in the feeding site (FS) experiment, the terminal leaflet was saturated with hundreds of mites that were allowed to feed for $1 \mathrm{hpi}$, following an experimental design described by Zhurov and associates (2014). RNA extracted from these samples was hybridized to the Affymetrix EUTOM3 tomato exon array. We detected 2,133 differentially expressed genes (DEG) in at least one timepoint as compared with noninfested control plants at an absolute fold change (FC) $>2$ and a Benjamini-Yekutieli (BY) false discovery rate (FDR) adjusted $P$ value $<0.01$, using the Bioconductor package limma (Benjamini and Yekutieli 2001; Smyth 2004) (Fig. 1; Supplementary Dataset S1). In the FS samples, we detected 1,936 DEG relative to the non-infested control at the cut-offs described above. Since the London spider mite strain was previously used for studies of Arabidopsis-mite interaction following the same timecourse and similar experimental design (Zhurov et al. 2014), we could perform a direct comparison between responses of these two plant species to the same herbivore. Approximately $50 \%$ of the DEG identified in the timecourse experiment and in the FS sample have putative bidirectional best hit $(\mathrm{BBH})$ orthologues in Arabidopsis (the establishment of the $\mathrm{BBH}$ orthologues between tomato and Arabidopsis is discussed below and is available in Supplementary Dataset S2) (Overbeek et al. 1999). Of the 2,133 DEG, 1,062 were up-regulated and 1,047 were down-regulated in at least one timepoint, with an additional 24 genes showing both significant up- and downregulation during the course of the experiment (Fig. 1A and C). Equal distribution between upand downregulated DEG in tomato contrasts with Arabidopsis responses that were largely represented by upregulation of gene expression (Zhurov et al. 2014). Tomato responses overlap considerably between different timepoints, with the greatest number of unique DEG being detected at 3 hpi (Fig. 1A). Validation of microarray results by reverse transcription-quantitative polymerase chain reaction (RT-qPCR) indicates that our microarray analysis is reproducible in capturing gene expression changes induced by spider mite herbivory (Supplementary Fig. S1).

In a principal component analysis, the majority of variance in gene expression was due to the factor attributable to spider mite treatment and number of mites deposited on a plant (PC1, $20 \%$ of total variation). The factor attributable to time postinfestation (PC2) explained another 18\% of the total variation in the data, reflecting a division between early and late responses, with early ( 1 and $3 \mathrm{hpi}$ ) and late timepoints (12 and $24 \mathrm{hpi}$ ) clustering together and the $6 \mathrm{hpi}$ timepoint found midway between these clusters (Fig. 1B).

Gene Ontology $(G O)$ analysis. To characterize differentially regulated programs upon spider mite feeding, we wanted to identify GO categories enriched in DEG but found that the International Tomato Annotation Group (ITAG) GO annotation (Sato et al. 2012) associated with the tomato genome was limited in scope. Thus, we performed complete GO re-annotation of tomato proteins, using the Blast2GO workflow (Conesa et al. 2005). The Blast2GO annotation of the EUTOM3 microarray platform increased the number of annotated genes to 22,966 ( $80 \%$ of genes interrogated by microarray) compared with 18,340 (64\% of genes interrogated by microarray) annotated by ITAG v.2.4 GO. The number of unique terms associated with genes represented on the microarray increased from 1,965 to 5,668 , and the mean number of GO terms associated with a gene increased to 6.1 from 1.3 terms per gene. Despite a substantial increase in the number of GO terms associated with genes, the mean average distance of term to the GO root only slightly decreased to 5.6 compared with 6.1 in the original annotation, indicating that the Blast $2 \mathrm{GO}$ annotation also maintained the level of specificity of the original GO annotation. For example, terms pertinent for our study that were signifi- 
cantly improved include: GO:0009753 'response to jasmonic acid'-136 genes associated in the current annotation; GO:0009751 'response to salicylic acid' -57 genes; and GO:0010466 'negative regulation of peptidase activity'-19

A
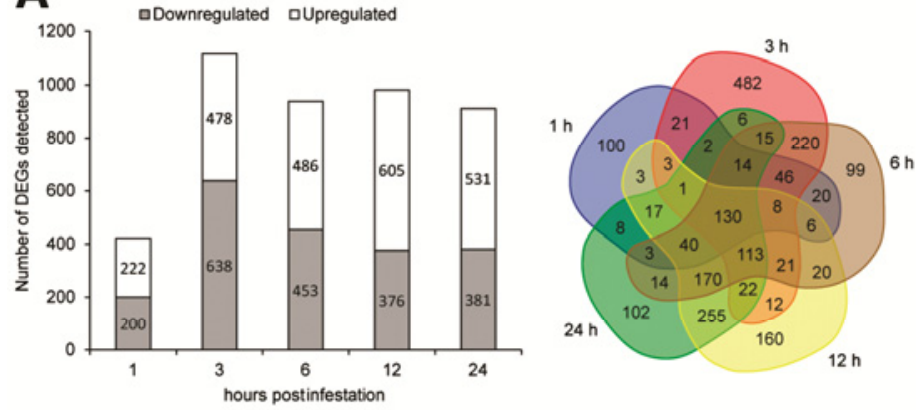

C

Expression measures of DEG detected in the timecourse
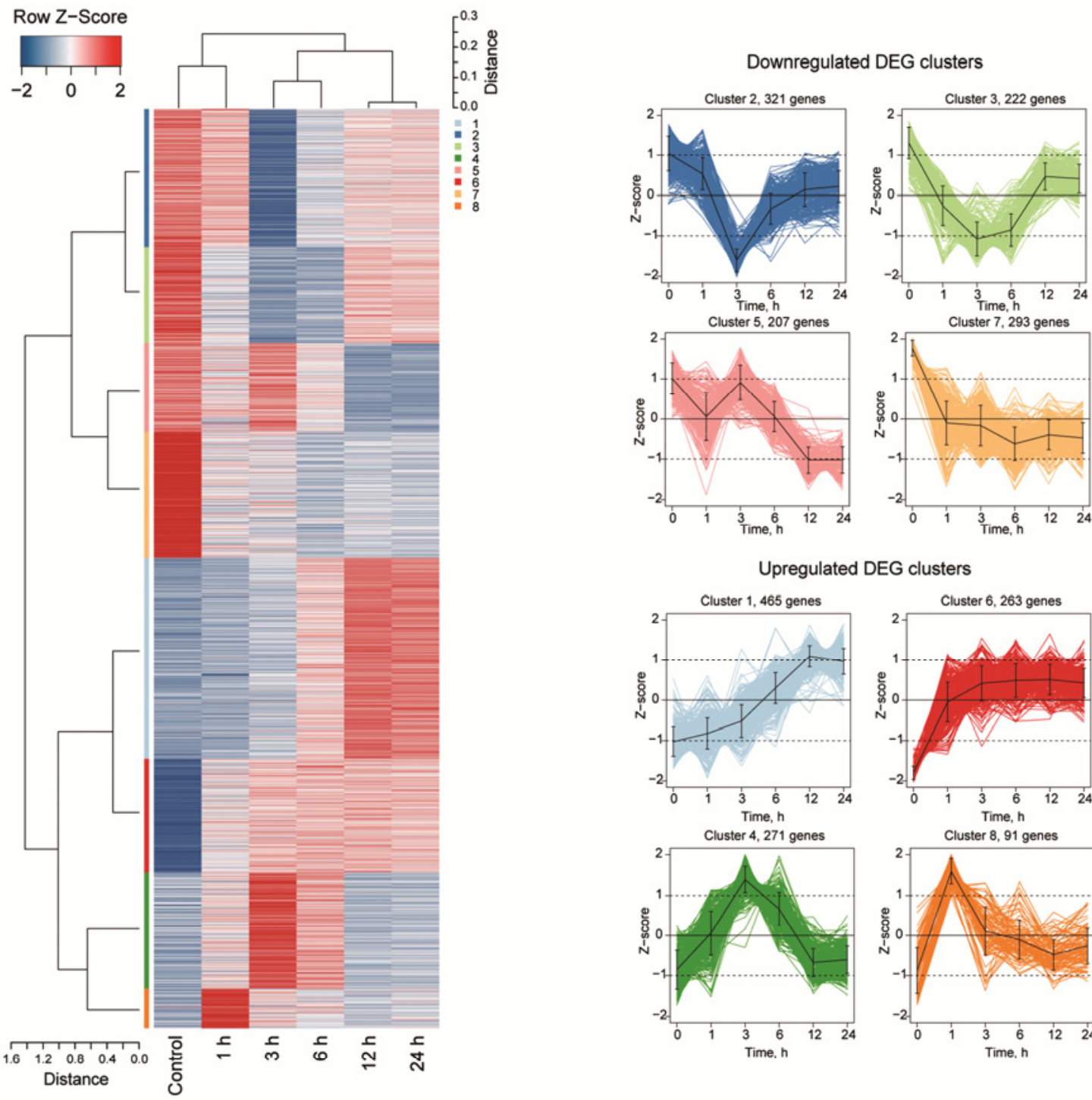

Upregulated DEG clusters
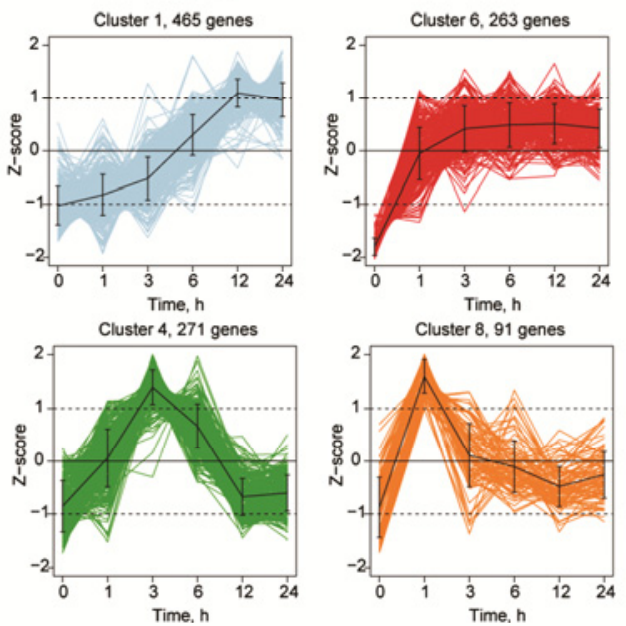

Gene clustering: $k$-means, $k=8$, distance - Pearson's correlation

Sample and center clustering: hierarchichal, distance - Pearson's correlation, linkage - average

Fig. 1. Microarray analysis of tomato response to spider mite herbivory. A, Number and directionality of differentially expressed genes (DEG) in tomato upon spider mite herbivory in timecourse samples and Venn diagram of lists of DEG. B, Principal component analysis of microarray expression data for timecourse (1 to $24 \mathrm{~h}$ ) and feeding-site (FS) samples. C, Clustering analysis and heat map of expression measures of DEG detected in timecourse samples and expression graphs of individual DEG clusters. 
plants to JA treatment (discussed below) and ultimately included 274 tomato genes. The updated GO annotation is available as Supplementary Dataset S3.

GO analysis of biological processes (BP) revealed that DEG detected in the timecourse experiment samples were enriched in genes involved in defense responses common to many biotic and abiotic stresses, including categories such as 'response to jasmonic acid', 'response to wounding', 'negative regulation of peptidase activity', 'response to stress', and 'jasmonic acid biosynthetic process' (Supplementary Dataset S4 includes a list of the top $50 \mathrm{GO} \mathrm{BP}$ ). Cluster analysis of DEG expression indicated that the transcriptional response developed in stages, starting with the perception of spider mite attack, followed by metabolic reprogramming, and ultimately resulting in the establishment and maintenance of a defense response (Fig. 1C).

Gene set enrichment analysis. In order to understand and visualize the dynamic development of tomato transcriptional response to spider mite attack, we performed gene set enrichment analysis (GSA) using a parametric analysis of gene set enrichment (PAGE) algorithm (Kim and Volsky 2005) of the complete list of 2,133 DEG detected in the timecourse experiment, using gene level statistics ( $\log _{2}$ fold change, adjusted $P$ value and $t$ statistic) estimated by limma for each timepoint as an input. GO annotation was used to classify genes into sets with BP and cellular component (CC) ontologies treated separately. The distinct changes in gene set regulation were analyzed as described in Varemo and associates (2013).

A total of 60 gene sets based on the BP GO annotation were found to be significantly up- or downregulated in the timecourse samples (Fig. 2; Supplementary Fig. S2, for node labels for BP GO category terms can be found in). The identity of the gene sets at different timepoints highlights distinct stages of tomato responses to spider mite feeding.

At $1 \mathrm{hpi}, 26 \mathrm{BP}$ GO-based gene sets associated with perception of the attack were detected as differentially regulated (FDR adjusted $P$ value $<0.05$ ) with processes related to protein phosphorylation, cell signaling, and response to wounding being the most strongly upregulated and processes related to anabolism being suppressed. Closer examination of the identity of the kinases present in the 'protein phosphorylation' gene set reveals that they comprise mostly of receptor-like kinases (RLK). Certain gene sets showed transient upregulation exclusively at $1 \mathrm{hpi}$, including those associated with perception of herbivory and signal transduction, programmed cell death, and transport of metabolites and vesicles. In contrast, other gene sets remained differentially expressed throughout the full timecourse, such as 'response to wounding' and 'response to jasmonic acid stimulus' that were up-regulated and anabolismrelated gene sets that were down-regulated.

At $3 \mathrm{hpi}$, only seven gene sets were detected as distinctly up- or downregulated, despite the highest number of DEG detected at this timepoint (1,166 DEG). Upregulated GO BP categories corresponding to responses to JA stimulus and wounding, and downregulated categories corresponding to chloroplast relocation and photosystem II assembly were similarly detected as differentially regulated in all other samples, indicating that these constitute the core defense programs. The low number of DEG sets relative to the high number of DEG detected at this timepoint is likely due to the shifting of transcriptional responses from initial perception and signaling at 1 hpi towards production of defense compounds against herbivore detected at 6 hpi onwards.

In later timepoints, distinct transcriptional reprogramming was established with 10, 41, and 32 gene sets detected as differentially regulated at 6,12 , and $24 \mathrm{hpi}$, respectively. The gene sets overlapped considerably; all 10 gene sets detected at 6 hpi were stably differentially regulated at later timepoints as well, and 12- and 24-hpi samples shared 29 gene sets. These results demonstrated that, while stable activation of responses to wounding and JA and suppression of anabolic processes occur in tomato very early upon spider mite herbivory, defense responses marked by secondary metabolite production and activation of proteinase inhibitors are established gradually at 6 to $12 \mathrm{hpi}$ and are maintained at $24 \mathrm{hpi}$.

GSA based on CC GO classification identified 17 gene sets throughout the timecourse. Early transcriptional responses were associated with cellular components responsible for perception and transcriptional reprogramming at 1 and 3 hpi and were followed by gene sets associated with cellular components involved in defense responses in 6- to 24-hpi samples (e.g., endoplasmic reticulum, Golgi apparatus, vacuole), consistent with BP categories enriched at these timepoints (Supplementary Fig. S3).

Induced transcriptional response at the FS. In order to robustly capture early and local responses, we also performed a FS experiment as described above. A total of 1,936 DEG were detected relative to the non-infested control, and 758 DEG were detected relative to tomato response at $1 \mathrm{hpi}$ in the timecourse scenario at the cut-offs described above (Supplementary Dataset S5). Transcriptional response in the FS sample demonstrated a considerable degree of overlap with both the response at $1 \mathrm{hpi}$ and responses that were detected in the later timepoints (Fig. 3A). GSA based on BP GO terms implicated 45 DEG sets in the FS sample (Fig. 3B). Differentially regulated gene sets in the FS sample demonstrated significant overlap with gene sets enriched in the timecourse sample. In all pair-wise comparisons, a substantial number of gene sets detected at the individual timepoints overlapped with FS DEG sets (Fig. 3C). At 1 hpi, 16 of 25 gene sets overlapped with 45 FS gene sets; at $3 \mathrm{hpi}$, five of seven; at $6 \mathrm{hpi}$, six of 10; at 12 hpi, 11 of 41 ; and at $24 \mathrm{hpi}$, nine of 32, indicating that i) tomato defense responses to spider mite herbivory is robustly established as early as $1 \mathrm{hpi}$, and ii) tomato defense responses to spider mite herbivory at later timepoints capture early responses as well, probably due to continuous mite feeding. Further analysis of 758 DEG detected between 1 hpi and FS samples by GSA revealed that BP associated with responses to JA, wounding, chitin, and fungus were enhanced under the FS scenario, while processes associated with anabolism were downregulated to a greater extent (Fig. 3D). Hierarchical clustering analysis demonstrated an enhancement of the response for the majority of the 758 DEG detected between $1 \mathrm{~h}$ and FS samples (irrespective of the directionality of the response) (Fig. 3E; Supplementary Dataset S6).

\section{Analysis of transcriptional responses of def-1 plants to JA treatment and spider mite herbivory.}

In tomato, JA signaling has been shown to be essential for the proper expression of a number of defense-related genes against spider mites (Ament et al. 2004; Kant et al. 2004; Li et al. 2002a; Li et al. 2004; Sarmento et al. 2011). Despite our improved $\mathrm{GO}$ annotation of the tomato genes by Blast2GO, well-known markers of JA responses such as LOXD, PI-I, PI$I I, L A P, T D$, and $P P O$ were absent from the 'response to jasmonic acid stimulus' category, indicating that homologybased approaches for gene function prediction are biased towards establishing similarity with model organisms (e.g., Arabidopsis) and require additional functional experiments for determination of species-specific functions. Thus, to determine the extent of JA regulation of tomato defense responses to spider mite herbivory, we performed an assay using the JA signaling mutant def- 1 (cv. Castlemart). def- 1 has normal basal levels of JA but fails to induce its accumulation in response to wounding and herbivory (Howe et al. 1996). To identify genes 

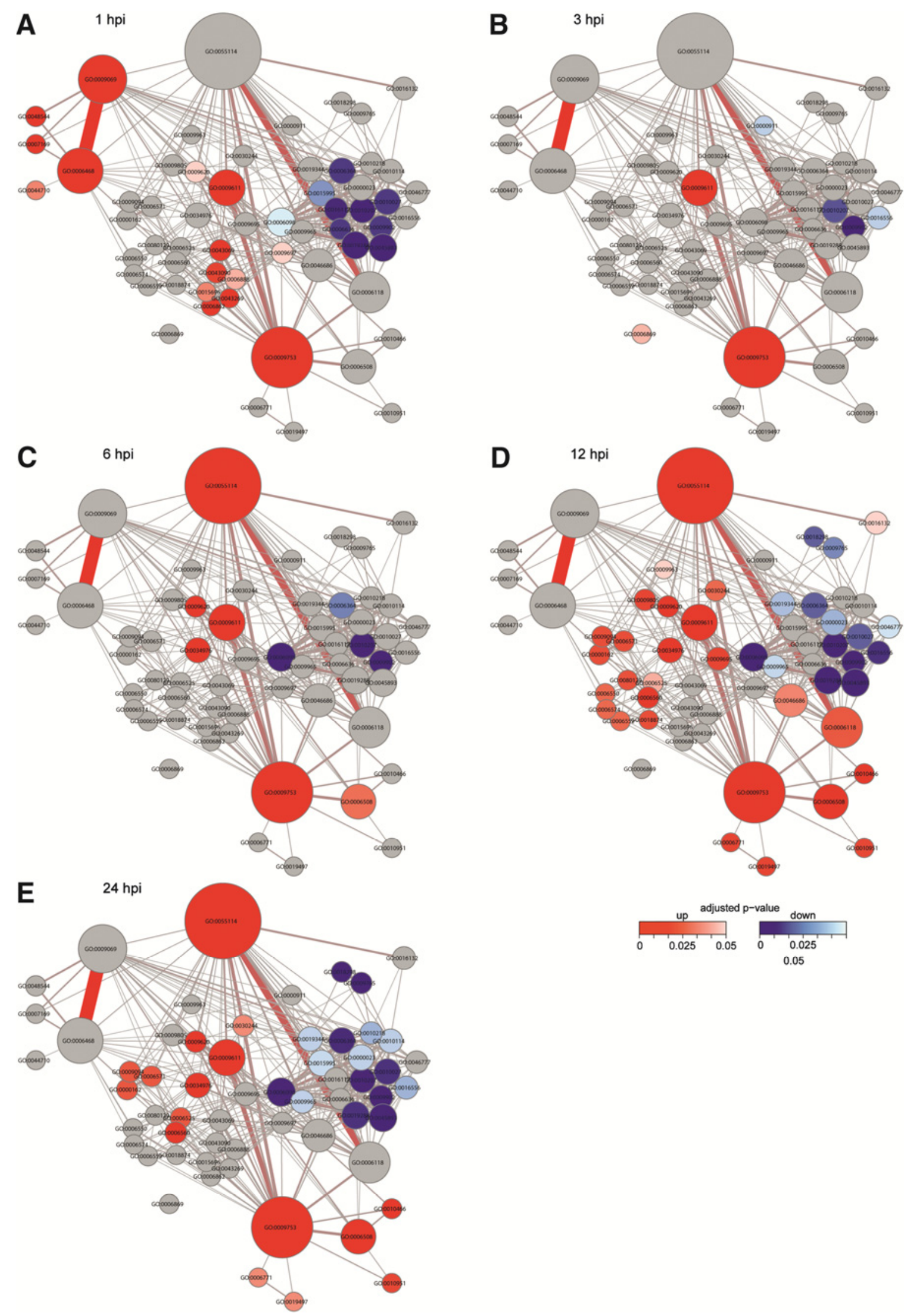

Fig. 2. Gene set enrichment analysis of biological processes for differentially expressed genes (DEG) detected in tomato timecourse samples upon spider mite herbivory. A to E, Union parametric analysis of gene set enrichment (PAGE) network based on Biological Processes (BP) Gene Ontology (GO) annotation with significantly enriched up- and downregulated gene sets in timecourse samples. Nodes represent gene sets, edges indicate the overlap in genes belonging to connected gene sets. Gene sets: blue = downregulated, red = upregulated, gray $=$ not detected as differentially regulated. Size corresponds to number of genes in a given gene set (five to 186), labels indicate BP GO category identification. The color (gray to red) and width of the edges correspond to an overlap size (1 to 79 ). 
A

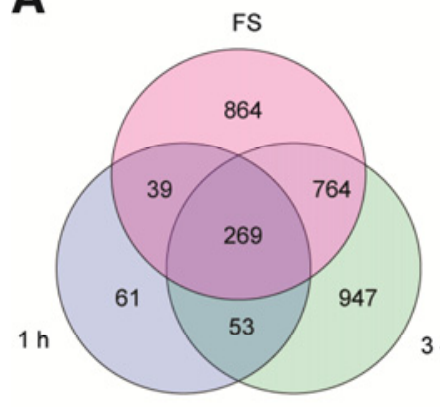

C

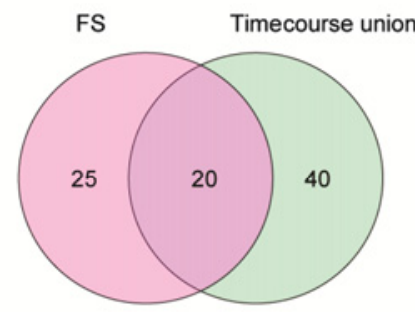

D

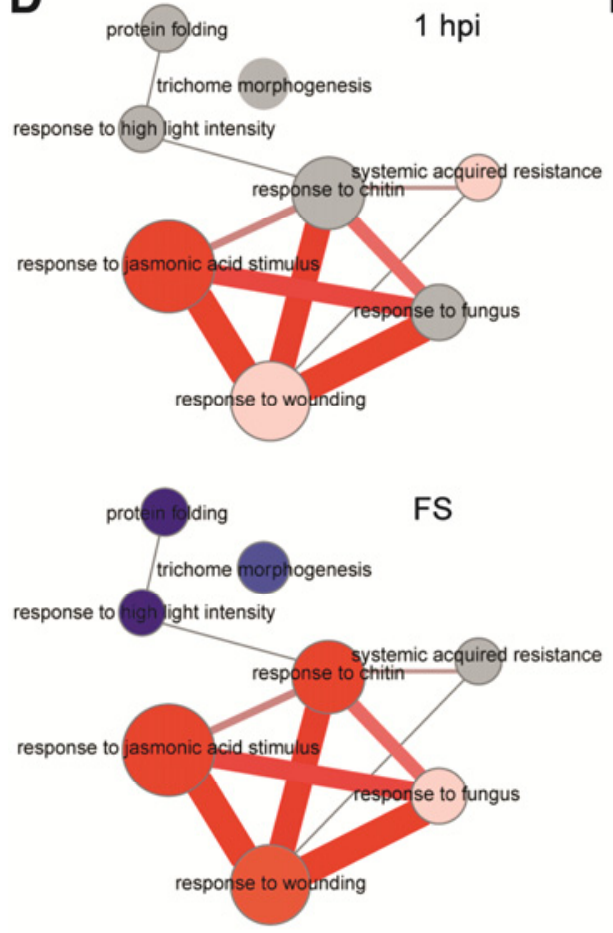

B $3-24 h$

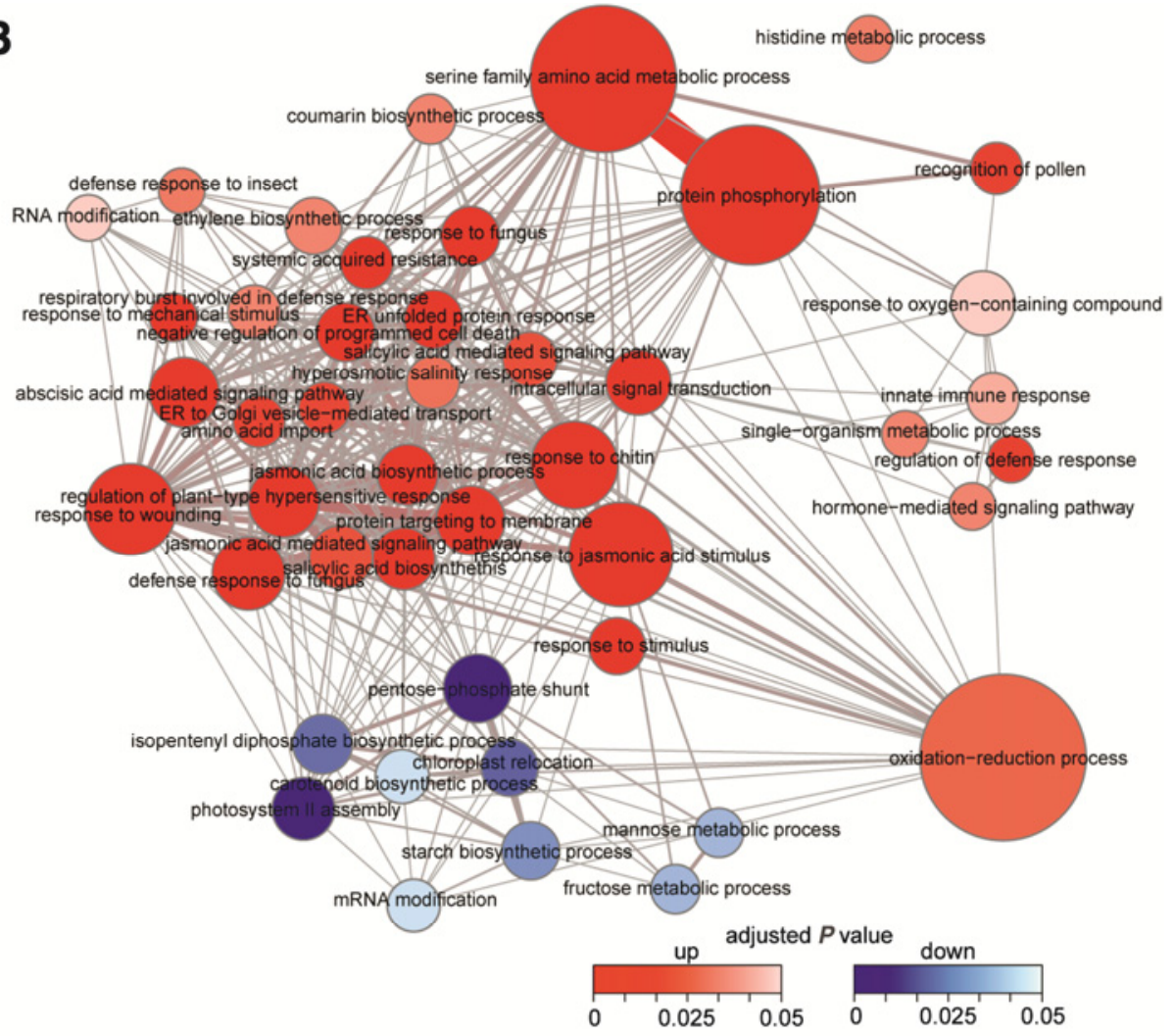

E Expression measures of DEG detected between $1 \mathrm{~h}$ and $\mathrm{FS}$ samples
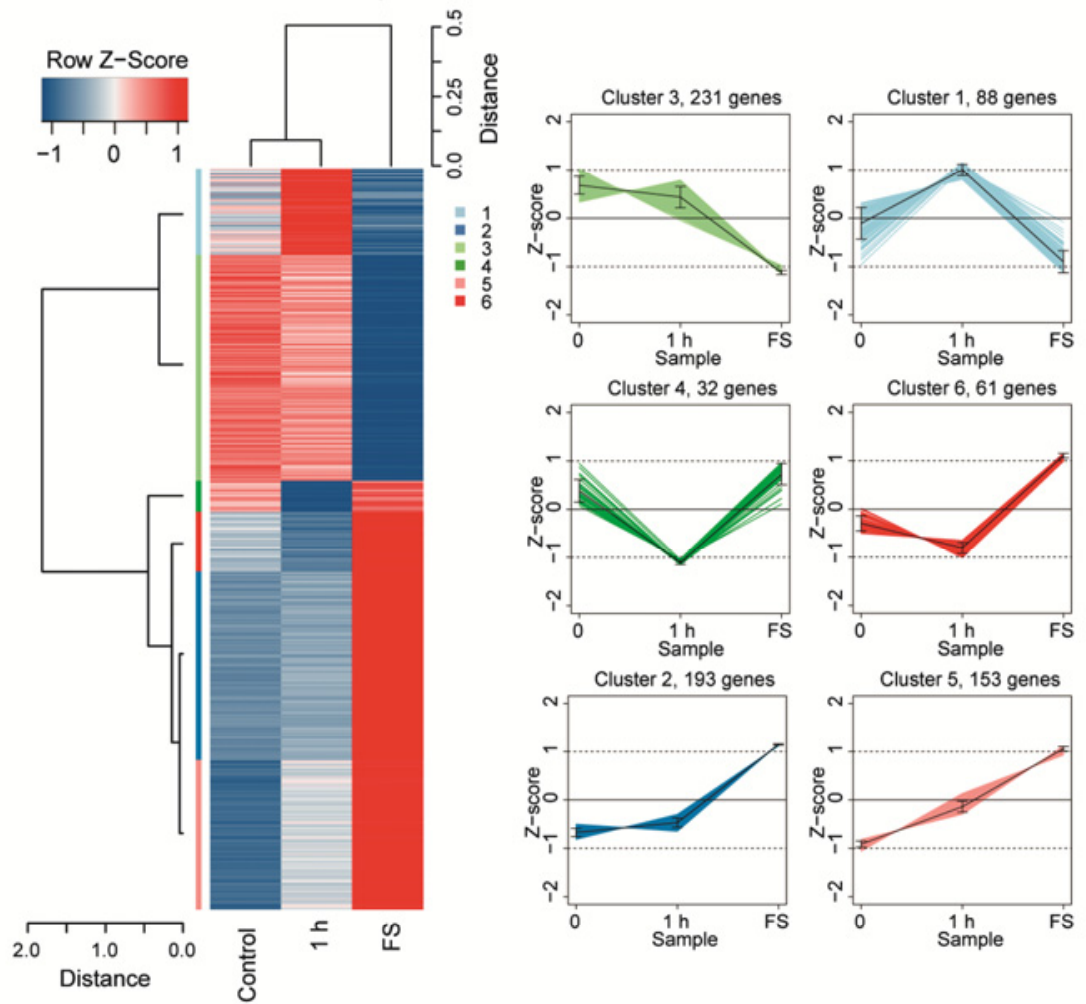

Gene clustering: $k$-means, $k=6$, distance - Pearson's correlation

Sample and center clustering: hierarchichal,

distance - Pearson's correlation, linkage - average 
whose expression is regulated by JA, def-1 plants were sprayed with exogenous JA. We tested a range of JA concentrations and determined that a $1 \mathrm{mM}$ JA solution is sufficient to reproducibly induce several known JA markers (Supplementary Fig. S4). We also infested def- 1 plants with 100 adult female spider mites to identify genes induced by spider mite feeding independently of an increase in JA levels. For each experiment, tissue was collected $24 \mathrm{~h}$ post-treatment. We found 1,324 and 225 genes to be differentially expressed by $1 \mathrm{mM} \mathrm{JA}$ and spider mite treatments, respectively, at the absolute $\mathrm{FC}>2$ and Benjamini-Hochberg (BH) FDR (Benjamini and Hochberg $1995)$ adjusted $P<0.05$ relative to mock-sprayed and noninfested plants, respectively (Supplementary Dataset S7). These experimentally derived JA-responsive genes were used to re-annotate the BP GO category GO:0009753 'response to jasmonic acid stimulus'. Based on limma estimated log-odds ratio (B) of being differentially expressed for known JA markers detected in JA-sprayed samples, an additional 129 DEG that demonstrated $\log$-odds ratio $(\mathrm{B})>10$ were included in this GO category, increasing the total number of tomato genes within the GO:0009753 'response to jasmonic acid stimulus' to 274 .

DEG detected in $\operatorname{def}-1$ by exogenous JA application were approximately equally split between up- (770) and downregulated (572) $24 \mathrm{~h}$ after treatment (Supplementary Fig. S5). Overall, based on GO enrichment analysis, this treatment closely resembled tomato response to herbivore attack, reinforcing the fact that JA signaling was identified as a major regulator of defense responses (Ament et al. 2004; Li et al. 2002a; Li et al. 2004; Schweighofer et al. 2007; P. J. Zhang et al. 2009; Zheng et al. 2007; Zhurov et al. 2014). Biological processes associated with plant defense response were represented by upregulated DEG, and processes associated with anabolism and growth were represented by downregulated DEG (Supplementary Dataset S8). DEG detected in def-1 after spider mite herbivory were mainly up- (207) rather than down-regulated (17). Based on GO analysis, these DEG represent a subset of genes inducible by JA signaling ('response to jasmonic acid' BP category), suggesting that some of these genes can be induced redundantly with or without an increase in JA concentration. In addition, the GO category 'salicylic acid biosynthetic process', reported to be activated later in the tomato defense response to spider mite herbivory (Kant et al. 2004), was also enriched, suggesting that evolutionary conserved antagonistic cross-talk between JA and SA signaling pathways (Thaler et al. 2012) may not be fully functional in def- 1 plants.

Comparison of the DEG identified in $d e f-1$ with the DEG detected in the 24-hpi timecourse sample allowed us to classify the latter genes in different categories reflecting their dependency on JA. A total of 322 genes were differentially regulated by both spider mite feeding on 'Heinz 1706' and by JA treatment of def-1, indicating that JA is sufficient to regulate their expression. Additionally, 39 genes were differentially regulated by spider mite attack in both 'Heinz 1706' and def-1 but not by JA treatment of $d e f-1$; thus, their expression is regulated by factors associated with mite herbivory independently of JA regulation. The majority of DEG, 503 genes, were differentially regulated by spider mite feeding on 'Heinz 1706' but not by either JA or spider mite treatments of $\operatorname{def}-1$ plants. These genes likely require the coordinated action of the JA and some other pathways activated upon spider mite feeding. Finally, 48 genes were differentially regulated by all three treatments. Thus, the expression of approximately $95 \%$ of DEG detected at $24 \mathrm{~h}$ upon spider mite feeding in 'Heinz 1706' are dependent on JA, indicating that this hormone has a pivotal role in establishing tomato defense responses against mite herbivory.

\section{Overview of tomato defense responses.}

Having determined genome-wide transcriptional responses in both tomato and Arabidopsis upon feeding by the same London strain of spider mites and within the same response time frame (this work; Zhurov et al. 2014), we can compare the complexity and conservation in spider mite-induced DEG between these plant species. Out of 2,133 tomato genes that are differentially expressed upon mite herbivory, 1,092 have Arabidopsis orthologues, and 360 of 841 Arabidopsis time-

Fig. 3. Analysis and comparison of FS and timecourse differentially expressed genes (DEG). A, Venn diagram of DEG detected in feeding site (FS) samples $1 \mathrm{~h}$ postinfestation (hpi) and 3 to $24 \mathrm{hpi}$. B, Gene set enrichment analysis of biological processes (BP) for DEG detected in tomato FS samples upon spider mite herbivory. Nodes represent gene sets, edges indicate overlap in genes belonging to connected gene sets. Gene sets: blue $=$ downregulated, red $=$ upregulated, gray $=$ not detected as differentially regulated. Size corresponds to the number of genes in a given gene set (five to 131). Labels are the BP Gene Ontology (GO) category identification. Color (gray to red) and width of edges correspond to an overlap size (1 to 86). C, Venn diagram of BP GO categories detected as differentially regulated by gene set enrichment analysis in FS and timecourse samples. D, Gene set enrichment analysis of BP for DEG detected between tomato FS and 1-h samples upon spider mite herbivory. Nodes represent gene sets, edges inidicate overlap in genes belonging to connected gene sets. Color is as in B, size corresponds to number of genes in a given gene set (five to 38). Labels are BP GO category identification. Color (gray to red) and width of edges correspond to an overlap size (1 to 10). E, Clustering analysis and heat map of expression measures of DEG detected between tomato FS and 1-h samples upon spider mite herbivory and expression graphs of individual DEG clusters.

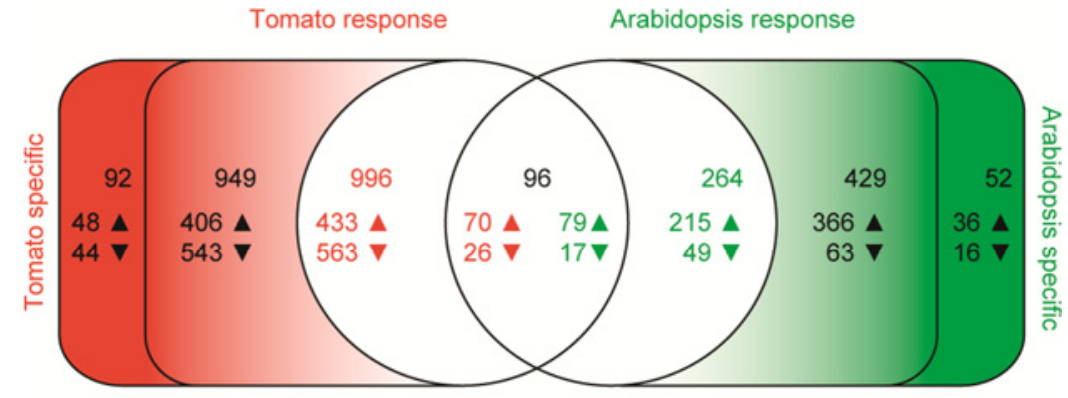

$\mathrm{BBH}$ orthologues

Potential homologues

Fig. 4. Analysis of phylogenetic relationships of differentially expressed genes (DEG) detected in tomato and Arabidopsis transcriptional responses to spider mite herbivory. 
course DEG (Zhurov et al. 2014) have tomato counterparts. Of these DEG, only 96 are induced by spider mite herbivory in both species (Fig. 4). The most prominent class of conserved core set of DEG is associated with JA biosynthesis and signaling ( $L O X 3$, LOX6, AOS, OPR3, OPCL1, ACX1, JMT, JAZ1, JAZ8, MYC2)

\section{Receptor-like kinases}

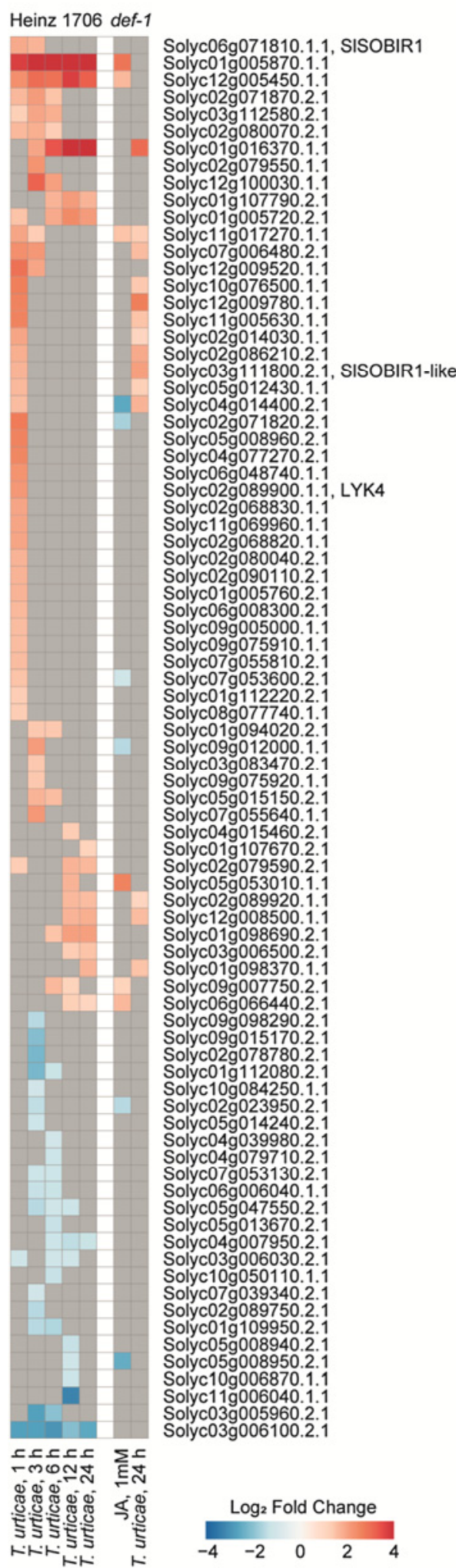

Fig. 5. Heat map of $\log _{2}$ fold changes of receptor-like kinases detected as differentially expressed in response to mite herbivory or jasmonic acid (JA) treatment in Heinz 1706 and def-1 tomato plants.
(Supplementary Dataset S9). In addition, several genes involved in the perception (receptor kinases) and $\mathrm{Ca}^{2+}$-signaling, biosynthesis of secondary metabolites (phenylpropanoids, flavonoids and isoprenoids), cell-wall modification, and endoplasmic reticulum (ER) stress are also present. It is striking that the remainder of DEG that represent one-to-one orthologous pairs and are, thus, assumed to have the same function in both species (996 differentially expressed in tomato and 264 in Arabidopsis) are induced in only one of the species, indicating profound divergence of species-specific transcriptional responses to spider mite herbivory. In tomato, a hallmark of this group of orthologous genes is a subset of downregulated DEG associated with anabolism processes. These genes potentially reflect a greater shift from growth to defense in tomato relative to Arabidopsis, which may be associated with different life history patterns between these species. The GO analysis of upregulated orthologous DEG (433 in tomato and 215 in Arabidopsis) demonstrates both conservation at the level of biological programs (such as further recruitment of genes to support the JA signaling cascade) and a divergence of responses (such as biosynthesis of various secondary metabolites). While the majority of DEG possess a degree of similarity (2,041 tomato DEG have Arabidopsis homologues and 789 Arabidopsis DEG have tomato homologues), there is a subset of DEG unique to respective responses (92 in tomato and 52 in Arabidopsis [Fig. 4]). About half of these species-specific DEG are uncharacterized. However, in Arabidopsis, four defensin-like $(D E F L)$ genes are differentially expressed in response to spider mite. DEFL gene families are expanded in Arabidopsis and are known to be recruited for a multitude of biological functions, including defense (Nguyen et al. 2014; Penninckx et al. 1996; Silva et al. 2014; Silverstein et al. 2005, 2007). On the other hand, in tomato, five PI lacking Arabidopsis homologues are differentially expressed. Thus, although JA is a conserved signaling hormone mediating responses to spider mite herbivory, the majority of plant defenses against spider mites are ultimately manifested as species (or at least plant family) -specific.

In order to highlight specific pathways that underlie tomato responses to spider mite herbivory, we combined annotations from Blast2GO analysis, the GOMapMan (Ramsak et al. 2014) and relevant literature to associate DEG with individual defense-related pathways.

\section{Defense responses conserved between tomato and Arabidopsis.}

Perception of spider mite herbivory. RLK play a critical role in the establishment of defense responses, as they are involved in the initial perception of extracellular elicitors originating from spider mites (herbivory-associated molecular patterns [HAMPs]) or damaged tissue resulting from mite feeding (damage-associated molecular patterns [DAMPs]). The mechanism by which either spider mites, tissue damage, or both are recognized by the plant is currently unknown. Following the paradigm of plant-pathogen interaction in which RLK involved in the perception of pathogen derived elicitors (PAMPs) are transcriptionally induced early upon PAMP recognition (Postel et al. 2010; Yamaguchi and Huffaker 2011), we reasoned that our data might include potential receptors involved in detection of spider mite feeding. A total of 82 RLK (identified based on the GOMapMan annotation) were differentially expressed in a timecourse sample upon spider mite attack (Fig. 5; Supplementary Dataset S10), a number of which were induced within the first $3 \mathrm{~h}$ of tomato response in a pattern expected from candidate receptors of spider mite feeding (including both HAMP and DAMP elicitors).

We further hypothesized that if plants perceive conserved elicitors associated with spider mite feeding, they will be rec- 
ognized by RLK that are conserved across plant species and will be induced by spider mite herbivory in both tomato and Arabidopsis. We identified eight such RLK, six of which encode leucine-rich repeat (LRR)-RLK whose function has not been tested in either tomato or Arabidopsis. However, two of them encode characterized receptors SUPPRESSOR OF BIRI-1 (SOBIRI) and LYSM-CONTAINING RECEPTOR-LIKE KINASE 4 (LYK4). Tomato expresses two homologues of AtSOBIR1, named SISOBIR1 (Solyc06g071810, whose transcripts are elevated during the first $3 \mathrm{~h}$ of mite feeding) and SlSOBIRl-like (Solyc03g111800, transiently induced by spider mite feeding during the first hour) (Fig. 5). SOBIRl genes encode a LRR-RLK, proposed to act as a co-receptor in complexes containing LRR-receptor-like proteins (RLP) (Liebrand et al. 2013, 2014), suggesting that LRR-RLP may play an important role in the recognition of spider mite feeding. $L Y K 4$, on the other hand, encodes an RLK with a peptidoglycan-binding LysM extracellular domain, shown to be involved in chitintriggered signaling (Wan et al. 2012). Intriguingly, the arthropod exoskeleton is composed of chitin, raising the possibility that carbohydrate patterns may be recognized as spider mite conserved elicitor.

Jasmonic acid. A prominent role of JA in regulating defenses against spider mites has been described for several plants (Ament et al. 2004; Li et al. 2002a; Li et al. 2004; Schweighofer et al. 2007; P. J. Zhang et al. 2009; Zheng et al. 2007; Zhurov et al. 2014), indicating that regulatory mechanisms leading to mite-induced defense programs are broadly conserved across plant species. Consistently, we found that genes encoding JA biosynthetic enzymes were induced by mite feeding in our dataset (Fig. 6). These biosynthetic enzymes are encoded by gene families and, in general, only some genes within these families were induced by mite herbivory. For example, out of 22 tomato LOX genes present in the GOMapMan annotation (Ramsak et al. 2014), only three were induced. The expression of $L O X D$ was up-regulated throughout the timecourse, consistent with its previous characterization as an early herbivory responsive gene (Heitz et al. 1997; Yan et al. 2013). Interestingly, LOXD expression also increased when $d e f-1$ plants were challenged with spider mites, suggesting that the initial increase in expression of some of the JA biosynthetic genes could be triggered in a JAindependent way. In contrast to $L O X D$, the expression of LOXA increased at later timepoints in both 'Heinz 1706' and def- 1 plants treated with JA, suggesting that its expression is controlled by a JA-regulated positive feedback loop consistent with a previous report (Beaudoin and Rothstein 1997)). Three $A O S$ genes showed upregulation in our dataset. AOS1 expression is rapidly and continuously upregulated from 1 to $24 \mathrm{~h}$. The def-1 microarray dataset indicates that expression of this gene is both JA sufficient and JA independent, as previously reported (Howe et al. 2000). AOS2 is also transiently upregulated at $12 \mathrm{~h}$, likely as a result of a JA positive feedback loop (our data; Howe et al. 2000). Unsurprisingly, the root-specific AOS3 gene (Itoh et al. 2002) is not detected. Allene oxide cyclase expression shows significant upregulation starting at 6 $\mathrm{h}$ after spider mite attack. Three OPDA (12-oxophytodienoate) reductase genes were identified in tomato $(O P R 1, O P R 2$ and $O P R 3)$; however, only $O P R 3$, shown to participate in JA biosynthesis (Strassner et al. 2002), had increased expression at 12 hpi in our dataset.

Like JA biosynthesis, perception and JA signaling are dependent on conserved proteins that are part of the ubiquitinproteasome system (COII) and transcriptional regulators (JAZ) (Chini et al. 2007; Feys et al. 1994; Li et al. 2004; Sheard et al. 2010; Thines et al. 2007; Xie et al. 1998). Twelve putative $J A Z$ genes have been identified in tomato (Ishiga et al. 2013), seven of which were up-regulated upon mite feeding in a JA-dependent way (e.g., being induced both by mite feeding on 'Heinz 1706' and upon JA treatment of def-1 plants). In Arabidopsis, the COI1-JAZ pathway regulates the expression of AtMYC2, a bHLH transcription factor (Kazan and Manners 2013). Two AtMYC2 homologues, JAMYC2 and JAMYC10 (Boter et al. 2004), were also induced by spider mite feeding (Fig. 6).

Expression levels of several genes have been used as markers of JA responses in tomato. These include the JA biosynthetic enzymes LOXD and AOSI, PI-I and PI-II, LAP, TD, and $P P O$. As expected, all of these marker genes were induced by spider mite feeding (in 'Heinz 1706') and JA (in def-1 mutant plants). They belong to clusters 1 (PI, LAP, TD, PPO) and 6 (LOXD, AOS1) of expression patterns shown in Figure 1, which contain 465 and 263 genes with similar expression patterns, respectively. This extensive list of coexpressed genes that are stably up-regulated after $12 \mathrm{hpi}$ supports the establishment of the tomato defense and will be an invaluable resource for future investigation of tomato-pest interaction.

Ethylene. ET is synthesized from $S$-adenosine methionine through the sequential action of enzymes 1-aminocyclopropane-1-carboxylic acid (ACC) synthase (ACS) and ACC oxidase (ACO). ACS enzymes are often regulated at post-transcriptional levels (Chae et al. 2003; Oetiker et al. 1997); thus, it was not unexpected to find that only a single putative $A C S$ gene (Solyc08g079750) showed altered expression out of the eight ACS genes annotated in the tomato genome (Lincoln et al. 1993; Nakatsuka et al. 1998; Olson et al. 1995; Rottmann et al. 1991; Shiu et al. 1998; Yip et al. 1992). Of the annotated 14 $A C O$ genes, 11 were differentially regulated, including characterized ACO1, ACO2, and ACO5 (Blume and Grierson 1997; Nakatsuka et al. 1998; Sell and Hehl 2005) that were up-regulated at various timepoints and duration during the initial $24 \mathrm{~h}$ of tomato response to spider mite feeding.

The signaling cascade downstream of ET synthesis involves perception by ER-localized receptors (Nr, ETR1-6), signaling by CTR1, and EIN2 leading to activation of the plant-specific transcription factor EIN3 (and other EIN3-like [EIL] transcription factors). EIN3 and other EIL transcription factors directly regulate a second tier of transcriptional regulators termed ET response factors (ERF) that regulate the expression of ETresponsive genes (Merchante et al. 2013). Several ERF genes have been characterized in tomato, including Pti4, Pti5, Pti6 (Gu et al. 2002; Zhou et al. 1997), Sl-ERF2 (Pirrello et al. 2006; Z. Zhang et al. 2009), TERF1 (Huang et al. 2004), TSRF1 (Zhang et al. 2008), JERF1 (Zhang et al. 2004), JERF3 (Wang et al. 2004), and ERF1-4 (Tournier et al. 2003). The expression of most of the early ET signaling components (CTR1, EIN2, EIN3) did not change in our experiment. Of the 20 annotated tomato $A P 2 / E R F$ genes, a subset was differentially regulated. However, as downstream ET components showed both up- and downregulation (Fig. 6B), it is difficult to assess the importance ET may have in the regulation of spider mite defense in tomato. Further experiments using ET mutants and ET treatments should help understand the importance of this hormone in tomato defense against spider mites.

Salicylic acid. SA is a master regulator of plant responses against biotrophic pathogens. Reciprocal antagonism between SA and JA has been described in at least 17 different species (Thaler et al. 2012) and is exploited by both pathogens and herbivores to manipulate plant defense responses (Bhavsar et al. 2007; Diezel et al. 2009; El Oirdi et al. 2011; Howe and Jander 2008; Musser et al. 2002). In tomato, exogenous application of SA has been shown to reduce JA biosynthesis and to inhibit defense responses against caterpillar herbivory (Chandok et al. 2004; Thaler et al. 2002, 2010). However, Kant and associates (2004) reported increased expression of 


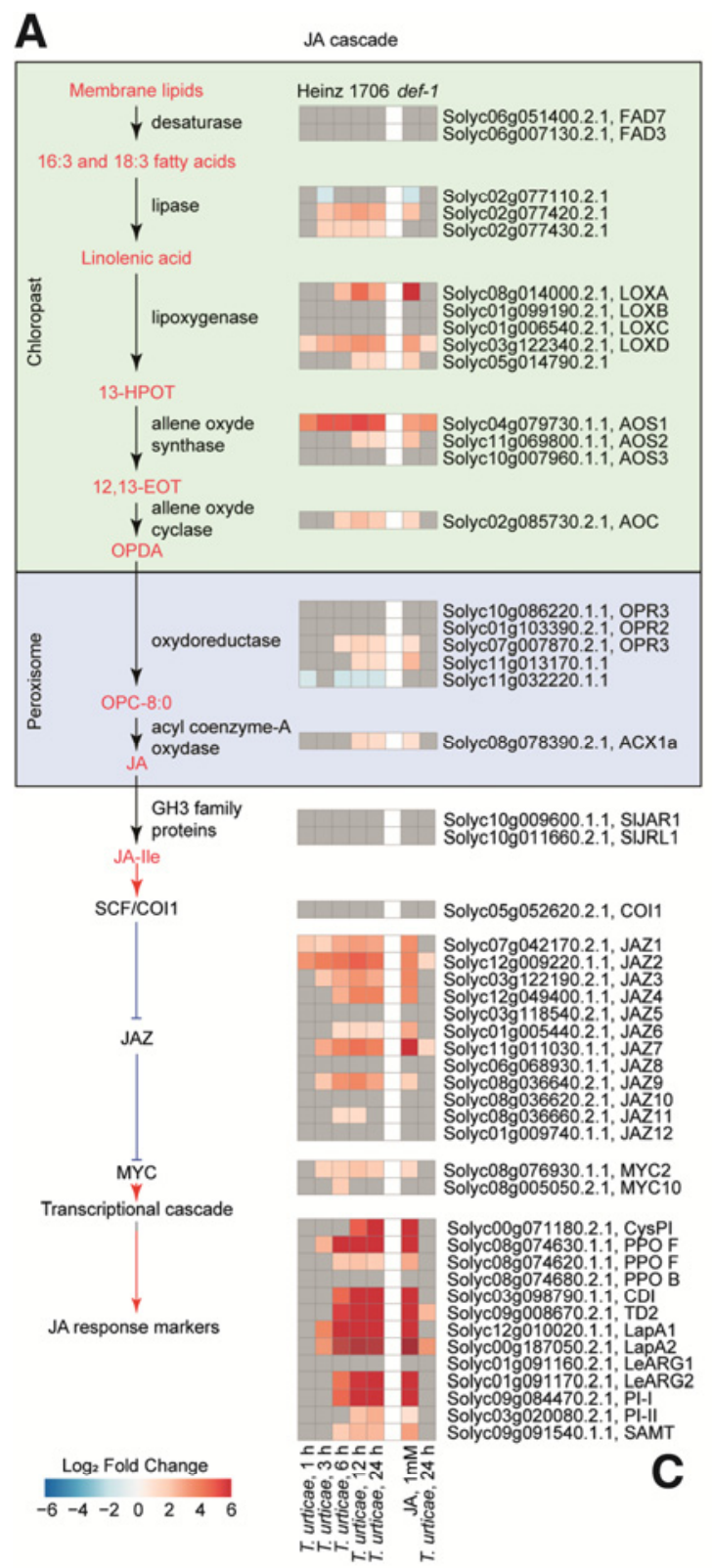

B

ET cascade
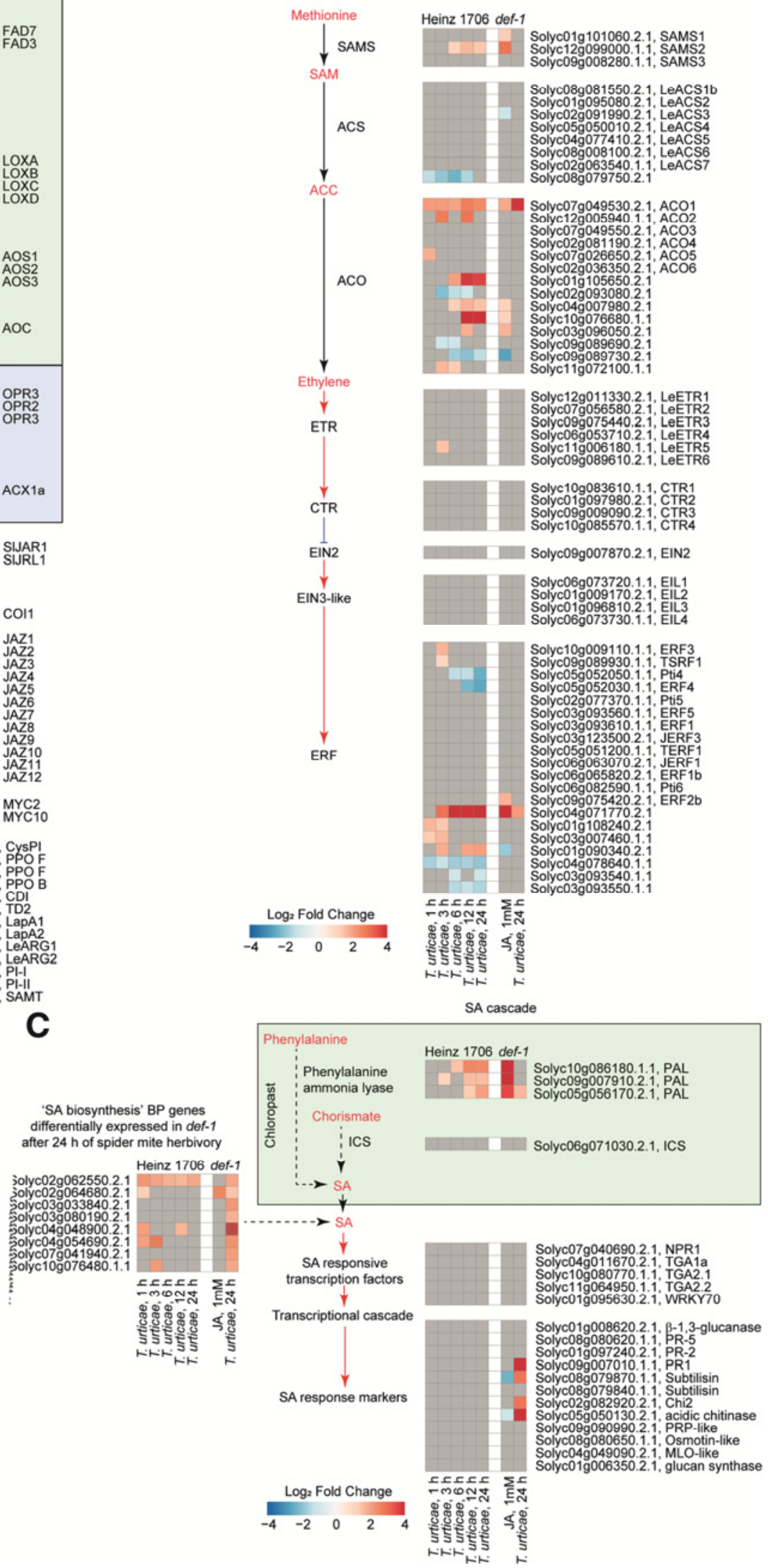

Fig. 6. Heat map of $\log _{2}$ fold changes of genes involved in plant hormone biosynthetic and signaling cascades and their downstream targets or markers in response to mite herbivory or jasmonic acid (JA) treatment in Heinz 1706 and def-1 tomato plants. A, JA biosynthesis, signaling, and response. B, Ethylene (ET) biosynthesis, signaling, and response. C, Salicylic acid (SA) biosynthesis, signaling, and response. In schemes of cascades, compounds are shown in dark red, proteins and enzymes in black, black arrows represent direct (solid) or indirect (dashed) biochemical transformations, red arrows indicate activation, and blue arrows indicate inactivation. 
A

Phenylalanine ammonia lyase, PAL

$\mathrm{N}$-acetyltransferase, $\mathrm{C} 4 \mathrm{H}$

4-coumarate-CoA ligase, $4 \mathrm{CL}$

Heinz 1706 def-1

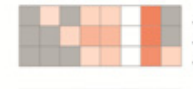

Solyc09g007910.2.1 Solyc05g056170.2.1

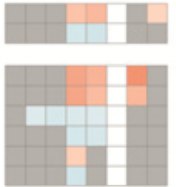

Solyc08g068730.1.1

(1.

Solyc03g117870.2.1

Solyc 05 g014510.2.

Solyc03g005090.2

Solyc12g094520.1.

Cytochrome P450, C3H

\begin{abstract}
Hydroxycinnamoyl-CoA shikimate/quinate hydroxycinnamoyl transferase. HCT

Caffeoyl-CoA O-methyl transferase, COMT
\end{abstract}

Cytochrome P450, F5H

Cinnamoyl-CoA reductase, CCR

Alcohol dehydrogenase, CAD

Unclassified

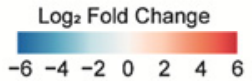

B

Flavonoids

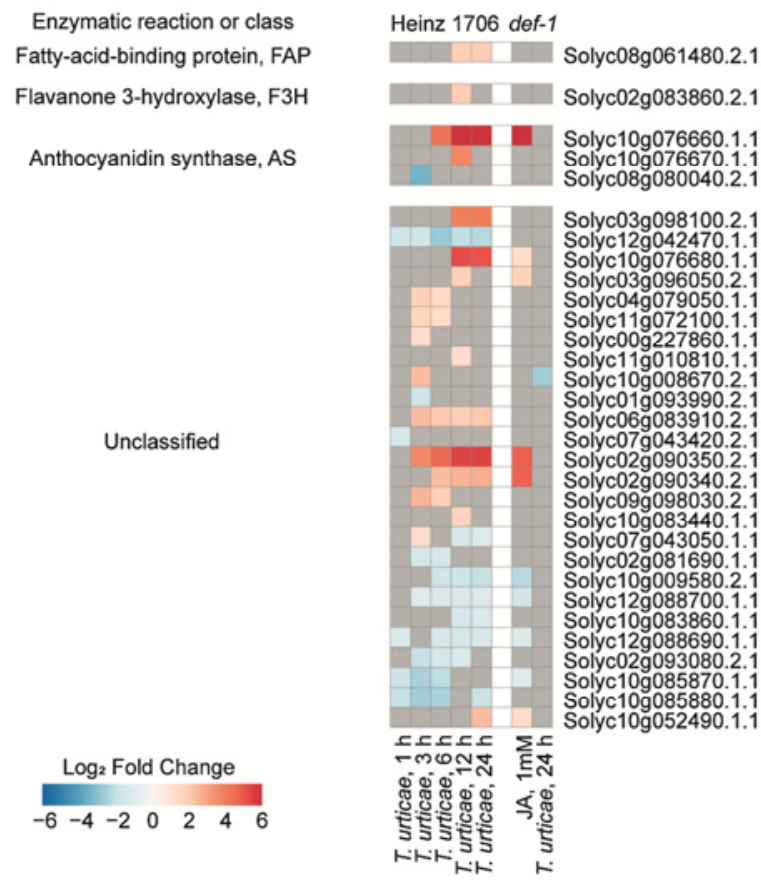

Solyc019096670.2. Solyc10g078240.1.1

Solyc11g071480.1.

Solyc11g071470.1.1
Solyc01g008300.1.1

Solyc02g093250.2.1

Solyc02g084570.2. Solyc04g050620.2.1
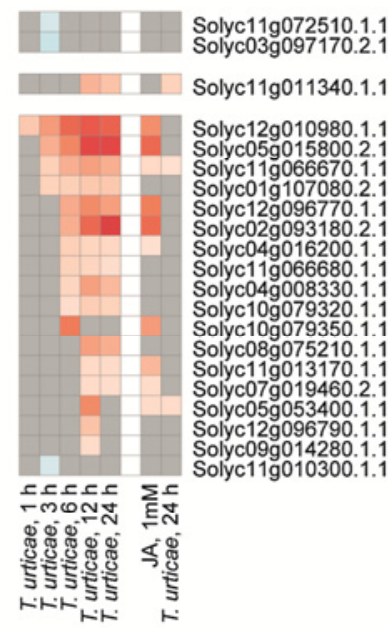

Solyc12g010980.1.1 Solyc05g015800.2. Solyc 019107080.2 Solyc02g093180.2. Solyc049016200.1.1 Solyc11g066680.1.1 Solyc04g008330.1.1 Solyc10g079350.1. Solyc08g075210.1. Solyc11g013170.1. Solyc05g053400.1. Solyc12g096790.1.1 Solyc11g010300.1.

$$
\begin{array}{lllllll}
-6 & -4 & -2 & 0 & 2 & 4 & 6
\end{array}
$$

Phenylpropanoids

Enzymatic reaction or class

C Isoprenoids, non-mevalonate pathway

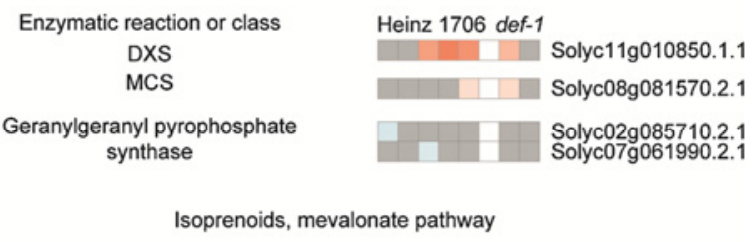

Acetyl-CoA C-acyltransferase

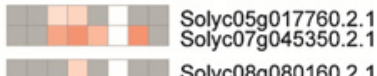

Hydroxymethylglutaryl-CoA synthase

Hydroxymethylglutaryl-CoA reductase

Solyc07g045350.2.

\begin{tabular}{|l|l|l|l|l}
\hline & Solyc08g080160.2.1 \\
Solyc08g080170.2.1
\end{tabular}

|| Solyc03g032010.2.1

Dephosphomevalonate decarboxylase

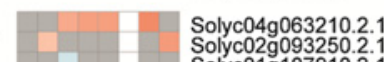

Farnesyl pyrophosphate synthase

Isopentenyl-diphosphate delta-isomerase

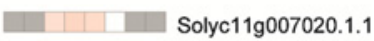

Dimethyllallyl pyrophosphate isomerase

\begin{tabular}{|l||l|}
\hline Solyc12g015860.1.1 & \\
\hline
\end{tabular}

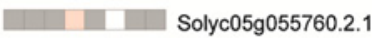

Isoprenoids, carotenoids

Unclassified

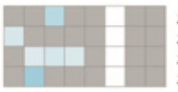

olyc06g036260.2. Solyc04g040190.1. Solyc02g081330.2.1 Solyc12g096770.1.

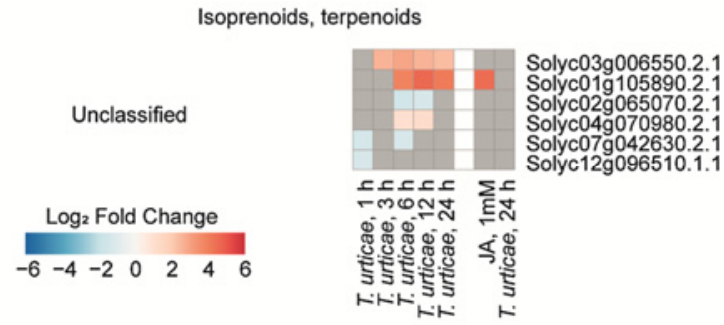

Fig. 7. Heat map of $\log _{2}$ fold changes of genes involved in biosynthesis of secondary metabolites such as A, phenylpropanoids, B, flavonoids, and $\mathbf{C}$, isoprenoids detected as differentially expressed in response to mite herbivory or jasmonic acid (JA) treatment in Heinz 1706 and def-1 tomato plants. 
both JA and SA marker genes at 1 and 4 days following spider mite herbivory, suggesting that mites can trigger both SA and JA pathways simultaneously. However, of SA biosynthetic genes, only three phenylalanine ammonia-lyase (PAL) genes were induced by mite feeding (Fig. 6C). These genes encode enzymes that are not specific for SA biosynthesis, as they also support the biosynthesis of phenylpropanoids, metabolites expected to accumulate upon mite herbivory (Fig. 7A). Thus, induction of $P A L$ gene expression may not be sufficient to predict accumulation of SA. In addition, none of the genes encoding SA signaling proteins nor commonly used SA markers (PR1, PR2, PR5, NPR1, subtilisin, chitinases) (Kant et al. 2004; Nachappa et al. 2013; Uehara et al. 2010) were differentially expressed when spider mites were feeding on 'Heinz 1706' plants, suggesting that mite feeding did not induce accumulation of SA within the first $24 \mathrm{hpi}$.

However, several genes associated with the GO category 'salicylic acid biosynthetic process', and a few SA markers (PR1 [Solyc09g007010], subtilisin-like protease [Solyc08g079870], and two chitinases [Solyc05g050130, Solyc02g082920]) were induced upon mite feeding on def- 1 plants (Fig. 6C). Furthermore, some of the SA marker genes were downregulated in $d e f-1$ plants treated with JA, suggesting that JAinduced pathways in wild-type plants can suppress spider mite-dependent SA responses. Observed differences in tomato responses to spider mite feeding described in our study and those performed by Kant and associates (2004) could be due to different timing of the responses, origin of the spider mite strains, differences between tomato cultivars and experimental set-ups, individually or in combination, used in assays. While Kant and associates (2004) used a tomato-adapted strain of spider mites, our experiments were performed with tomato nonadapted mites (London strain).

Phenylpropanoids and flavonoids. Our microarray dataset predicts an increased production of phenylpropanoids and flavonoids following spider mite infestation, as genes encoding several key enzymes involved in phenylpropanoid biosynthesis, such as PAL, cinnamate-4-hydroxylase, and 4-coumarateCoA ligase, were up-regulated following mite attack (Fig. 7). A total of 76 DEG were predicted to encode enzymes involved in the biosynthesis of phenylpropanoids and flavonoids based on the GOMapMan annotation (Ramsak et al. 2014). These biosynthetic pathways are well conserved between different plant species. In Arabidopsis, 44 genes are associated with the phenylpropanoid pathway, each one of which has a predicted tomato homologue, including 24 one-to-one orthologues at all enzymatic steps.

Compounds involved in indirect defenses. The homoterpene TMTT and MeSA constitute the most abundant volatiles produced by tomato in response to spider mite herbivory (Ament et al. 2004, 2006). Isoprenoids are synthesized by two pathways. One is the mevalonate pathway, which operates in the cytosol of higher plants, and the other is the nonmevalonate pathway, which is localized in chloroplasts (Kuzuyama 2002). Genes encoding enzymes acting in both of these pathways have been induced in tomato upon spider mite feeding (Fig. 7). Even though geranylgeranyl pyrophosphate synthase 1 has been suggested as the key regulator of TMTT accumulation (Ament et al. 2006), its expression levels did not change in response to spider mite attack. However, genes encoding other enzymes involved in terpenoid biosynthesis, such as mevalonate diphosphate decarboxylase (Solyc11g007020), DOXPsynthase (Solyc11g010850), and geranyllinalool synthase (Solyc03g006550) were up-regulated by spider mite attack, consistent with reported induced production of terpenoid-based volatiles (Ament et al. 2004, 2006). Similarly, upregulation of salicylic acid carboxyl methyltransferase genes following mite attack is also consistent with a predicted increase in MeSA production (Ament et al. 2004).

\section{Other tomato defense responses.}

$J A$-induced defense proteins that target herbivore digestive physiology. Commonly used markers of tomato induced defenses are LAPA1 and LAPA2, LeARG1 and LeARG2,TD2, and $P P O$, which encode proteins that act in the pest gut to reduce amino acid availability from ingested plant tissues. Arabidopsis does not have genes encoding PPO and TD2 (Chen et al. 2007; Tran et al. 2012) nor JA-inducible LAPA genes that have been recruited for defense in tomato (Bartling and Nosek 1994). These enzymes impact herbivores' digestive physiology within an alkaline $\mathrm{pH}$ range that is characteristic of lepidopteran midgut (Chen et al. 2004, 2007; Chung and Felton 2011; Fowler et al. 2009; Gonzales-Vigil et al. 2011; Gu et al. 1999) and have been shown to be ineffective against pests with acidic guts, such as the Colorado potato beetle (Felton et al. 1992; Gonzales-Vigil et al. 2011). Spider mites are expected to have acidic gut content (Carrillo et al. 2011; Erban and Hubert 2010), and thus, even though LAPA1 and LAPA2, $L e A R G 1$ and $L e A R G 2, T D 2$, and $P P O$ were used as useful markers of mite-induced tomato defenses, these defense compounds may have little or no effect on spider mite herbivory.

The PI gene family in tomato. PI act as antidigestive and defensive compounds by interacting with their target proteases in the arthropod gut (Benchabane et al. 2010; Bode et al. 2013; Carrillo et al. 2011; Ortego 2012; Santamaria et al. 2012; Schluter et al. 2010). In tomato, two serine PI (PI-I and PI-II) were shown to be consistently induced by spider mite attack (Kant et al. 2004, 2008; Li et al. 2002b). We identified a total of 95 PI genes in the tomato genome that can be classified into eight families based on their inhibition specificity to serine-, cysteine-, aspartyl-, and metalloproteases (Supplementary Dataset S11). This is in contrast to 38 PI that are annotated in Arabidopsis, demonstrating a great expansion of this class of proteins in the tomato genome. Of 95 tomato PI genes, 25 were differentially expressed upon spider mite feeding compared with only one in Arabidopsis (Fig. 8A; Supplementary Table $\mathrm{S} 1$ ). Tomato $P I$ genes are among the most highly induced DEG in our dataset, suggesting that they represent one of the major tomato defense response outputs upon spider mite herbivory. These $P I$ were also induced by JA in $d e f-1$ plants, demonstrating that JA is sufficient to coordinately regulate their expression. Phylogenetic analysis of tomato and Arabidopsis PI showed that defense response to spider mite attack is limited to genes belonging to tomato-specific expansions in I3 and I13 families (Fig. 8B and C). All but one of the induced PI lack an Arabidopsis BBH orthologue, indicating that they define tomato-specific members within expanded families that have acquired novel transcriptional regulation by JA and have been recruited for defense.

\section{Conclusions.}

Our study, focused on early genome-wide transcriptional responses of tomato (cv. Heinz 1706) to herbivory by the twospotted spider mite Tetranychus urticae (London strain), identified 2,133 DEG that defined gradual establishment of tomato responses to spider mite feeding within the first $24 \mathrm{~h}$ of interaction. In addition, the role of JA in the establishment of tomato defense responses against spider mites was tested by treating a tomato mutant defective in JA synthesis (def-1) with JA or by mites. The study highlighted the importance of JA as a regulator of mite-induced defenses, since differential expression of approximately $95 \%$ of DEG at $24 \mathrm{~h}$ required JA, reinforcing the conserved role of JA in regulating plant defenses against a broad spectrum of plant-associated organisms (Ament 
et al. 2004; Campos et al. 2014; De Geyter et al. 2012; Li et al. 2002b; Li et al. 2004; Schweighofer et al. 2007; P. J. Zhang et al. 2009; Zheng et al. 2007; Zhurov et al. 2014). The prominent role of JA in regulation of plant defenses triggered by a myriad of herbivores results in majorly overlapping responses within a plant species, indicating that induced defenses may lack herbivore specificity. In particular, tomato defenses targeting herbivore digestive physiology are expected to vary in their effectiveness due to the heterogeneity of herbivore gut environments.

The previous study of Arabidopsis responses to spider mite attack in a similar timecourse experiment allowed us to compare tomato and Arabidopsis transcriptional changes upon spider mite feeding. Indole glucosinolates, secondary metabolites characteristic for cruciferous plants, were identified as major defense compounds in Arabidopsis against mites (Zhurov et al.
A in response to spider mite attack (Heinz 1706 and def-1) and JA treatment (def-1)

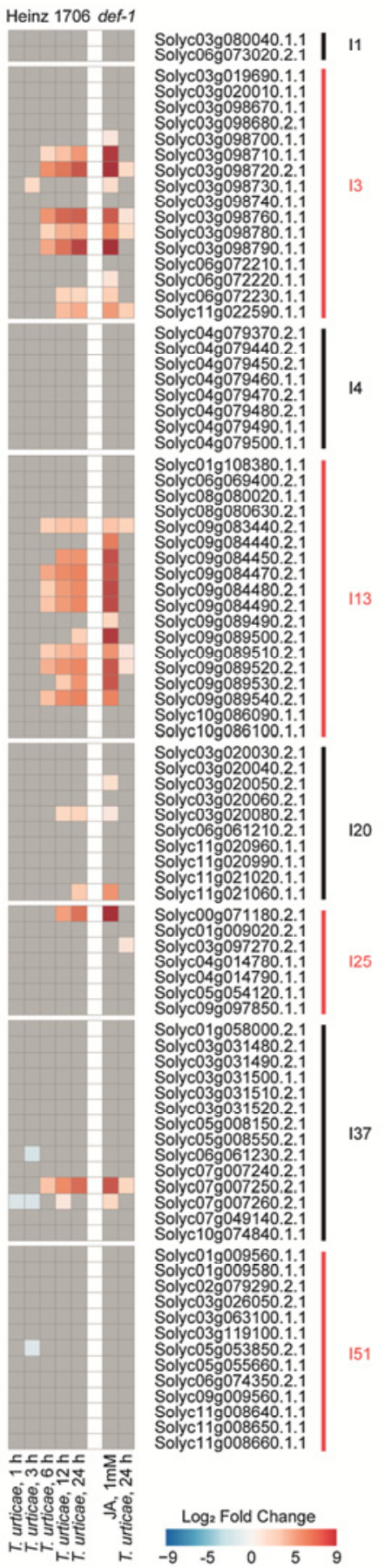

B

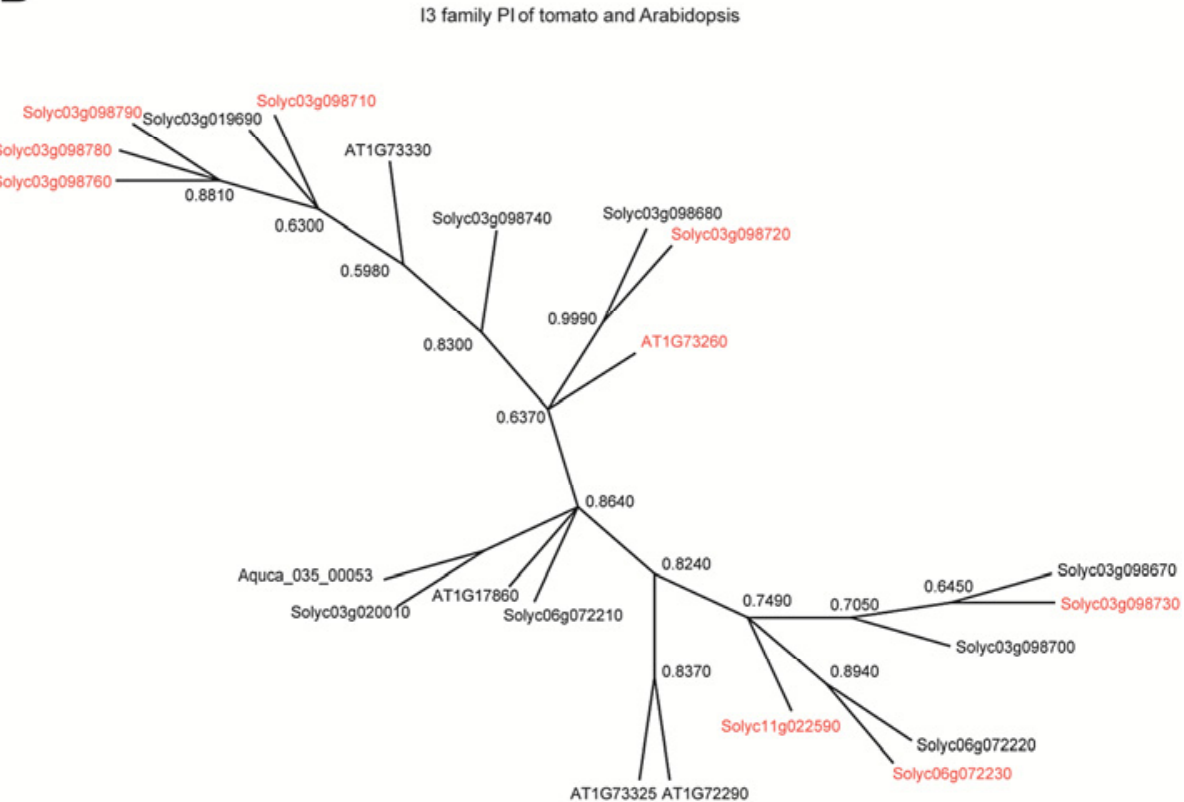

C

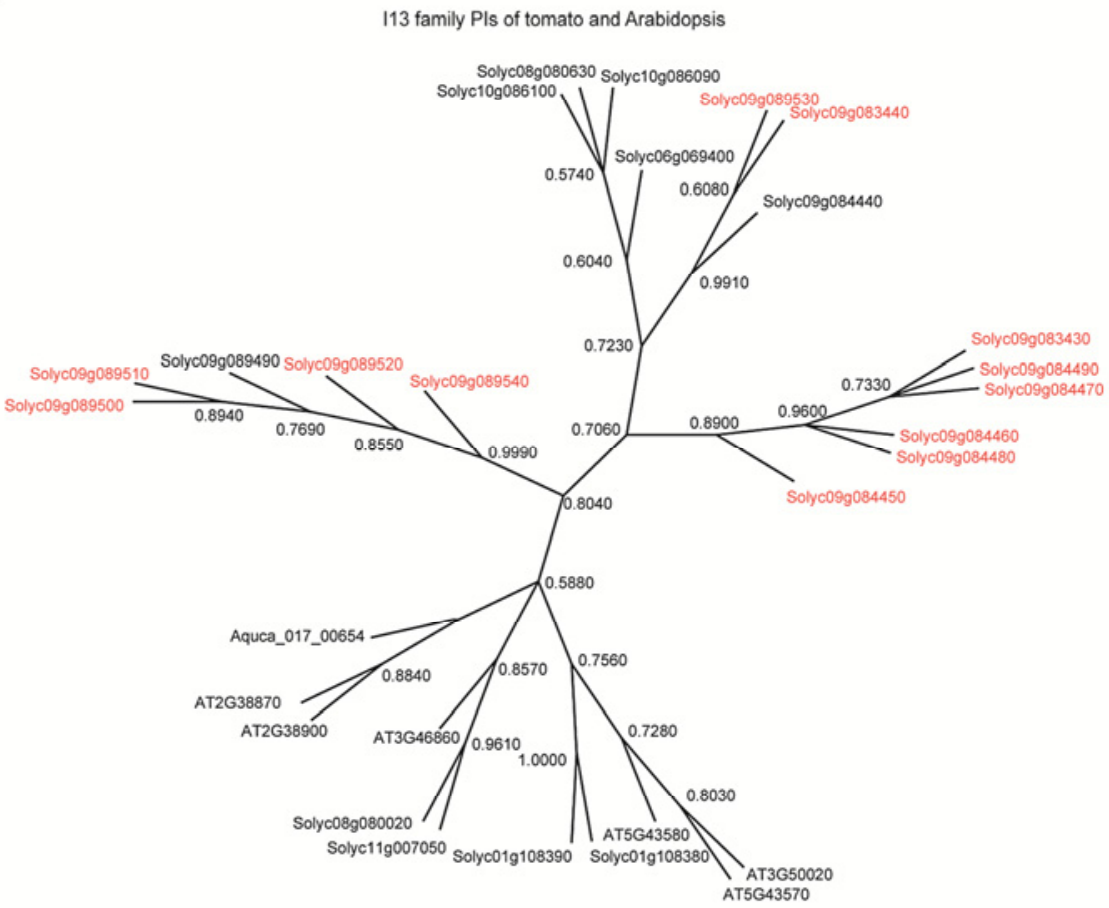

Fig. 8. Lineage-specific expansion of I3 and I13 peptidase inhibitor families in tomato is associated with antiherbivory function. A, Heat map of $\log _{2}$ fold changes of proteinase inhibitors (PI) genes in response to mite herbivory or jasmonic acid (JA) treatment in Heinz 1706 and def-1 tomato plants. B and $\mathbf{C}$, Unscaled cladograms of peptide sequences of I3 and I13 PI from tomato and Arabidopsis. PI highlighted in red are up-regulated in response to spider mite attack. Node labels are Shimodaira Hasegawa-like approximate likelihood ratio test (SH-aLRT) values. PI sequences from Aquilegia coerulia were used as outgroups. 
2014), while the syntheses of defense proteins that target herbivore digestive physiology appear as a prominent part of tomato-induced defenses upon mite herbivory. Even though the concept of diversification of plant defenses against herbivores has been postulated (Agrawal 2007; Berenbaum and Zangerl 2008; Mithofer and Boland 2012), our study identified the striking magnitude of differential transcriptional responses of Arabidopsis and tomato to the same herbivore. Thus, despite the conservation of the JA core signaling pathway, this analysis points to the profound evolutionary divergence of JA-regulated downstream defense responses between tomato and Arabidopsis contributing to future analysis of the evolution of plant chemical diversity. Gene duplication is considered to be one of the major sources of plant chemical diversification (Kroymann 2011; Ober 2010). Several tomato defense genes against herbivory (e.g., $T D 2, P P O, P I$ ) arose from gene duplication, followed by the acquisition of transcriptional regulation by JA. Systematic analysis of genes recruited for defense within the speciesspecific family expansions would determine how widespread this pattern might be. Identification of coexpressed gene clusters, integration of tomato metabolomic and transcriptomic responses, and functional analysis of individual DEG will, in the future, lead to the identification of tomato-specific defense compounds used to deter spider mite herbivory.

\section{MATERIALS AND METHODS}

\section{Plant and mite rearing.}

Tetranychus urticae (London strain) was mass reared on potted bean plants (Phaseolus vulgaris 'California Red Kidney Bean', Stokes) in a climate room with diurnal and night temperatures fluctuating between 26 and $20^{\circ} \mathrm{C}, 60 \% \pm 20 \%$ relation humidity, and with a photoperiod of $16 \mathrm{~h}$ of light and $8 \mathrm{~h}$ of dark. To obtain cohorts of adult females of similar age, 100 female mites were placed on separated leaves two weeks before the experiment, allowing them to lay eggs for $24 \mathrm{~h}$, after which they were removed. The offspring of the synchronized population was used for the infestation experiment. Potted tomato plants (cv. Heinz 1706 and def-1 [cv. Castlemart]) were grown under growth-chamber conditions with a $25^{\circ} \mathrm{C}$-light and $22^{\circ} \mathrm{C}$-dark cycle, 50 to $70 \%$ relative humidity, and a photoperiod of $16 \mathrm{~h}$ of light and $8 \mathrm{~h}$ of dark.

\section{Tomato response}

to spider mite attack microarray experiment.

In the spider mite feeding timecourse scenario, $100 \mathrm{~T}$. urticae adult females were applied on a terminal leaflet of leaf 3 of 21- to 24-day-old tomato plants and were allowed to feed for $1,3,6,12$, or $24 \mathrm{~h}$ in an experimental design described previously (Zhurov et al. 2014). In the FS scenario, the terminal leaflets were covered with hundreds of mites that were allowed to feed for $1 \mathrm{~h}$. Leaves whose terminal leaflet was inoculated by mites were harvested and used for RNA extraction. Three biological replicates representing two plants each were generated per treatment. Spider mites remained localized within the inoculated leaves without a need to restrain their movement. Experimental and control plants were kept in the same growth room. Total RNA was prepared using the RNeasy plant RNA extraction kit (Qiagen, Venlo, The Netherlands). RNA was hybridized to the EUTOM3 whole-genome exon microarray according to manufacturer's specifications (Affymetrix, Santa Clara, CA, U.S.A.). Analysis was performed using the Bioconductor framework (Gentleman et al. 2004). An initial dataquality assessment was conducted using arrayQualityMetrics (Kauffmann et al. 2009). Expression measures were computed using Robust Multi-array Average (RMA) on the complete data set (Irizarry et al. 2003). Detection of DEG was per- formed using limma with adjusted (BY) $P$ values (Benjamini and Yekutieli 2001; Smyth 2004). Clustering of mean expression measures of DEG was performed using $k$-means clustering with $k=8$, followed by ordering of gene clusters by hierarchical clustering with average linkage of $k$-means cluster centers. R session random seed was 25845159. Sample clustering was performed by hierarchical clustering with average linkage. Centered Pearson's correlation was used as a distance metric in all cases.

\section{def-1 response to spider mite attack}

and JA treatment microarray experiment.

For the JA treatment, 24- to 28-day-old plants were sprayed with either a control (mock) $0.5 \%$ (vol/vol) ethanol and water or a $1 \mathrm{mM}$ JA (Sigma-Aldrich, St. Louis) solution in $0.5 \%$ (vol/vol) ethanol and water. This concentration was chosen because it induced the most robust accumulation of the JA marker gene TOMWIPII (Sarmento et al. 2011) in 'Heinz 1706' plants treated with varying concentrations of JA. For mite infestation, 100 Tetranychus urticae (London strain) adult females were applied to the terminal leaflet of leaves 3 and 4 of 28-day-old plants. Three biological replicates representing two plants each were generated per treatment. Total RNA was prepared using the RNeasy plant RNA extraction kit (Qiagen). Analysis was performed using the Bioconductor framework (Gentleman et al. 2004). An initial data quality assessment was conducted using arrayQualityMetrics (Kauffmann et al. 2009). Expression measures were computed using RMA on the complete data set (Irizarry et al. 2003). Detection of DEG was performed using limma with adjusted $(\mathrm{BH}) P$ values (Benjamini and Hochberg 1995; Smyth 2004).

\section{GO re-annotation of tomato genome.}

GO re-annotation of tomato proteins using the Blast $2 \mathrm{GO}$ workflow (Conesa et al. 2005) was performed as follows. We performed blastp (Altschul et al. 1997) searches of the ITAG v.2.3 release of tomato protein sequences against a local copy of the National Center for Biotechnology Information nonredundant database (release 2013-10-20). InterProScan v.5.144.0 (Hunter et al. 2012; Jones et al. 2014) was performed locally against PANTHER data v.8.1 (Mi et al. 2005). Results were integrated into the $\mathrm{GO}$ annotation using Blast $2 \mathrm{GO}$ v.2.7.0 and local copy of the 2013-10 releases of Blast2GO and GO associations databases, using default stringency and Annex annotation augmentation (Myhre et al. 2006).

\section{GO annotation of gene lists.}

We have used topGO with the Fisher's test statistic and "weight01" algorithm (Alexa et al. 2006) to generate a list of the top 50 Biological Process GO annotations and annotation lists of genes that were detected as differentially expressed. The lists were further filtered by applying a cut-off of 0.05 to Fisher's weighted $P$ values.

\section{Gene set enrichment analysis.}

Gene set enrichment analysis was performed using a custom version of Bioconductor package piano (Varemo et al. 2013). $\log _{2}$ fold changes, $P$ and $t$ values obtained using limma were used as input gene level statistics for the analysis. Following comparison of implemented gene set analysis methods, a PAGE algorithm (Kim and Volsky 2005) was utilized. GO annotation was used to classify genes into sets with biological process and molecular function and cellular component ontologies treated separately. We limited analysis to gene sets that had at least five genes associated with them and used an adjusted (BH) $P$ value cut-off of 0.05 to determine significance of distinct up- or downregulation of a gene set. 
Establishment of bidirectional best hit orthologues between tomato and Arabidopsis.

To determine one-to-one orthologues using the BBH approach (Overbeek et al. 1999), reciprocal blastp (Altschul et al. 1997) searches were conducted using the ITAG v.2.3 release of tomato and the TAIR10 release of Arabidopsis protein sequences. Output files were further processed to retain $\mathrm{BBH}$ pairs with $\mathrm{E}<10^{-4}$.

\section{Genome-wide identification}

of tomato $P I$ and phylogenetic analysis.

Initially, the MEROPS database (Rawlings et al. 2014) of proteinases and their inhibitors was used to establish the PI families present in plants by looking for the distribution of each family in the different groups and then, blastp (Altschul et al. 1997) searches for PI were performed in the publicly available tomato and Arabidopsis genome databases. Blast searches were made in a recurrent way. First, a complete amino acid plant sequence from data banks corresponding to a protein of the family was used. Then, the obtained tomato or Arabidopsis protein sequences were used to search for PI in the tomato or Arabidopsis genome, respectively.

The obtained I3 and I13 PI family amino acid sequences were aligned using MUSCLE v.3.8.31 with the default parameters (Edgar 2004). Alignments were further processed using the Gblocks v.0.91b server, allowing for smaller blocks and less strict flanking positions (Castresana 2000). The final block alignments contained 53 amino acid positions for I13 and 42 amino acid positions for I3 PI families. Phylogenetic tree reconstruction was performed using PhyML (v. 20120412) (Guindon et al. 2010) with the LG amino acid substitution model (Le and Gascuel 2008). The approximate likelihoodratio test, based on a Shimodaira-Hasegawa-like procedure, was used as a statistical test for nonparametric branch support (Anisimova and Gascuel 2006). The resulting trees were visualized using Dendroscope (Huson et al. 2007), with Aquilegia caerulea used as an outgroup.

\section{Real-time RT-qPCR and data analysis.}

Total RNA was extracted using RNeasy plant mini kit, including DNase treatment (Qiagen). Total RNA $(2 \mu \mathrm{g})$ was reverse transcribed using the Maxima first strand cDNA synthesis kit for RT-qPCR (Thermo Fisher Scientific, Waltham, MA, U.S.A.). qPCR reactions were performed in triplicate for each biological replicate, using Maxima SYBR Green/ROX qPCR Master Mix (Thermo Fisher Scientific). The RT-qPCR was performed on an Agilent Mx3005P qPCR instrument (Agilent Technologies, Santa Clara, CA, U.S.A.). Primer sequences and amplification efficiencies (E) are listed in Supplementary Table 2. ACTIN (Solyc03g078400.2.1) was used as a reference gene. Threshold cycle $\left(\mathrm{C}_{t}\right)$ values of technical replicates were averaged to generate the $\mathrm{C}_{\mathrm{t}}$ of a biological replicate. For plotting, the expression value for each target gene (T) was normalized to the reference gene $(\mathrm{R})$, and the normalized relative quantity (NRQ) was calculated as follows. NRQ $=(1+$ $\left.E_{R}\right)^{\mathrm{CtR}} /\left(1+E_{T}\right)^{\mathrm{CtT}}$. For statistical analysis, NRQ values were $\log _{2}$-transformed and analysis of variance (ANOVA) was used to assess the significance of the main effect (JA concentration) (Rieu and Powers 2009). ANOVA was followed by Tukey's honestly significant difference test.

\section{ACKNOWLEDGMENTS}

This project was funded by the Government of Canada through Genome Canada and the Ontario Genomics Institute (OGI-046) (to M. Grbic and V. Grbic), Ontario Research Fund-Global Leadership in Genomics and Life Sciences GL2-01-035 (to M. Grbic and V. Grbic) and by the French Agence Nationale de la Recherche (ANR 2010 BLAN 1715 02) (to M. Navajas). T. Van Leeuwen is a postdoctoral fellow of the Fund for Scientific Research Flanders (FWO). This work was supported by FWO Grants 3G061011 and 3G009312. N. Wybouw has been supported by the Institute for the Promotion of Innovation by Science and Technology in Flanders (grant IWT/SB/101451). We thank T. Negrave for help with the manuscript.

\section{LITERATURE CITED}

Agrawal, A. A. 2007. Macroevolution of plant defense strategies. Trends Ecol. Evol. 22:103-109.

Alexa, A., Rahnenfuhrer, J., and Lengauer, T. 2006. Improved scoring of functional groups from gene expression data by decorrelating GO graph structure. Bioinformatics 22:1600-1607.

Altschul, S. F., Madden, T. L., Schaffer, A. A., Zhang, J., Zhang, Z., Miller, W., and Lipman, D. J. 1997. Gapped BLAST and PSI-BLAST: A new generation of protein database search programs. Nucleic Acids Res. 25:3389-3402.

Ament, K., Kant, M. R., Sabelis, M. W., Haring, M. A., and Schuurink, R. C. 2004. Jasmonic acid is a key regulator of spider mite-induced volatile terpenoid and methyl salicylate emission in tomato. Plant Physiol. 135:2025-2037.

Ament, K., Van Schie, C. C., Bouwmeester, H. J., Haring, M. A., and Schuurink, R. C. 2006. Induction of a leaf specific geranylgeranyl pyrophosphate synthase and emission of (E,E)-4,8,12-trimethyltrideca1,3,7,11-tetraene in tomato are dependent on both jasmonic acid and salicylic acid signaling pathways. Planta 224:1197-1208.

Anisimova, M., and Gascuel, O. 2006. Approximate likelihood-ratio test for branches: A fast, accurate, and powerful alternative. Systems Biol. 55:539-552.

Antonious, G. F., Kamminga, K., and Snyder, J. C. 2014. Wild tomato leaf extracts for spider mite and cowpea aphid control. J. Environ. Sci. Heal. B 49:527-531.

Bartling, D., and Nosek, J. 1994. Molecular and immunological characterization of leucine aminopeptidase in Arabidopsis thaliana: A new antibody suggests a semi-constitutive regulation of a phylogenetically old enzyme. Plant Sci. 99:199-209.

Beaudoin, N., and Rothstein, S.J . 1997. Developmental regulation of two tomato lipoxygenase promoters in transgenic tobacco and tomato. Plant Mol. Biol. 33:835-846.

Benchabane, M., Schluter, U., Vorster, J., Goulet, M. C., and Michaud, D. 2010. Plant cystatins. Biochimie 92:1657-1666.

Benjamini, Y., and Hochberg, Y. 1995. Controlling the False Discovery Rate-A Practical and Powerful Approach to Multiple Testing. J. Roy. Stat. Soc. B Met. 57:289-300.

Benjamini, Y., and Yekutieli, D. 2001. The control of the false discovery rate in multiple testing under dependency. Ann. Statist. 29:1165-1188.

Berenbaum, M. R., and Zangerl, A. R. 2008. Facing the future of plantinsect interaction research: Le Retour a la "Raison d'Etre". Plant Physiol. 146:804-811.

Bhavsar, A. P., Guttman, J. A., and Finlay, B. B. 2007. Manipulation of host-cell pathways by bacterial pathogens. Nature 449:827-834.

Blauth, S. L., Churchill, G. A., and Mutschler, M. A. 1998. Identification of quantitative trait loci associated with acylsugar accumulation using intraspecific populations of the wild tomato, Lycopersicon pennellii. Theor. Appl. Genet. 96:458-467.

Bleeker, P. M., Mirabella, R., Diergaarde, P. J., VanDoorn, A., Tissier, A., Kant, M. R., Prins, M., de Vos, M., Haring, M. A., and Schuurink, R. C. 2012. Improved herbivore resistance in cultivated tomato with the sesquiterpene biosynthetic pathway from a wild relative. Proc. Natl. Acac. Sci. U.S.A. 109:20124-20129.

Blume, B., and Grierson, D. 1997. Expression of ACC oxidase promoterGUS fusions in tomato and Nicotiana plumbaginifolia regulated by developmental and environmental stimuli. Plant J. 12:731-746.

Bode, R. F., Halitschke, R., and Kessler, A. 2013. Herbivore damageinduced production and specific anti-digestive function of serine and cysteine protease inhibitors in tall goldenrod, Solidago altissima L. (Asteraceae). Planta 237:1287-1296.

Boter, M., Ruiz-Rivero, O., Abdeen, A., and Prat, S. 2004. Conserved MYC transcription factors play a key role in jasmonate signaling both in tomato and Arabidopsis. Genes Dev. 18:1577-1591.

Campos, M. L., Kang, J. H., and Howe, G. A. 2014. Jasmonate-triggered plant immunity. J. Chem. Ecol. 40:657-675.

Carrillo, L., Martinez, M., Ramessar, K., Cambra, I., Castanera, P., Ortego, F., and Diaz, I. 2011. Expression of a barley cystatin gene in maize enhances resistance against phytophagous mites by altering their cysteine-proteases. Plant Cell Rep. 30:101-112.

Castresana, J. 2000. Selection of conserved blocks from multiple align- 
ments for their use in phylogenetic analysis. Mol. Biol. Evol. 17:540552

Chae, H. S., Faure, F., and Kieber, J. J. 2003. The eto1, eto2, and eto3 mutations and cytokinin treatment increase ethylene biosynthesis in Arabidopsis by increasing the stability of ACS protein. Plant Cell 15:545559.

Chandok, M. R., Ekengren, S. K., Martin, G. B., and Klessig, D. F. 2004 Suppression of pathogen-inducible NO synthase (iNOS) activity in tomato increases susceptibility to Pseudomonas syringae. Proc. Natl. Acad. Sci. U.S.A. 101:8239-8244.

Chen, H., McCaig, B. C., Melotto, M., He, S. Y., and Howe, G. A. 2004. Regulation of plant arginase by wounding, jasmonate, and the phytotoxin coronatine. J. Biol. Chem. 279:45998-46007.

Chen, H., Wilkerson, C. G., Kuchar, J. A., Phinney, B. S., and Howe, G. A 2005. Jasmonate-inducible plant enzymes degrade essential amino acids in the herbivore midgut. Proc. Natl. Acad. Sci. U.S.A. 102:1923719242.

Chen, H., Gonzales-Vigil, E., Wilkerson, C. G., and Howe, G. A. 2007. Stability of plant defense proteins in the gut of insect herbivores. Plant Physiol. 143:1954-1967.

Chini, A., Fonseca, S., Fernandez, G., Adie, B., Chico, J. M., Lorenzo, O. Garcia-Casado, G., Lopez-Vidriero, I., Lozano, F. M., Ponce, M. R., Micol, J. L., and Solano, R. 2007. The JAZ family of repressors is the missing link in jasmonate signalling. Nature 448:666-671.

Chung, S. H., and Felton, G. W. 2011. Specificity of induced resistance in tomato against specialist lepidopteran and coleopteran species. J. Chem. Ecol. 37:378-386.

Clavijo McCormick, A., Unsicker, S. B., and Gershenzon, J. 2012. The specificity of herbivore-induced plant volatiles in attracting herbivore enemies. Trends Plant Sci. 17:303-310.

Conesa, A., Gotz, S., Garcia-Gomez, J. M., Terol, J., Talon, M., and Robles, M. 2005. Blast2GO: A universal tool for annotation, visualization and analysis in functional genomics research. Bioinformatics 21:3674-3676.

De Geyter, N., Gholami, A., Goormachtig, S., and Goossens, A. 2012. Transcriptional machineries in jasmonate-elicited plant secondary metabolism. Trends Plant Sci. 17:349-359.

Dearden, P. K., Donly, C., and Grbic, M. 2002. Expression of pair-rule gene homologues in a chelicerate: Early patterning of the two-spotted spider mite Tetranychus urticae. Development 129:5461-5472.

Dermauw, W., Wybouw, N., Rombauts, S., Menten, B., Vontas, J., Grbic, M., Clark, R. M., Feyereisen, R., and Van Leeuwen, T. 2013. A link between host plant adaptation and pesticide resistance in the polyphagous spider mite Tetranychus urticae. Proc. Natl. Acac. Sci. U.S.A. 110:E113-122.

Dicke, M., Takabayashi, J., Posthumus, M. A., Schutte, C., and Krips, O. E. 1998. Plant-phytoseiid interactions mediated by herbivore-induced plant volatiles: Variation in production of cues and in responses of predatory mites. Exp. Appl. Acarol. 22:311-333.

Diezel, C., von Dahl, C. C., Gaquerel, E., and Baldwin, I. T. 2009. Different lepidopteran elicitors account for cross-talk in herbivory-induced phytohormone signaling. Plant Physiol. 150:1576-1586.

Edgar, R. C. 2004. MUSCLE: Multiple sequence alignment with high accuracy and high throughput. Nucleic Acids Res. 32:1792-1797.

El Oirdi, M., El Rahman, T. A., Rigano, L., El Hadrami, A., Rodriguez, M C., Daayf, F., Vojnov, A., and Bouarab, K. 2011. Botrytis cinerea manipulates the antagonistic effects between immune pathways to promote disease development in tomato. Plant Cell 23:2405-2421.

Erban, T., and Hubert, J. 2010. Determination of $\mathrm{pH}$ in regions of the midguts of acaridid mites. J. Insect Sci. 10:42. Published online.

Felton, G. W., Workman, J., and Duffey, S. S. 1992. Avoidance of antinutritive plant defense: Role of midgut $\mathrm{pH}$ in Colorado potato beetle. $\mathrm{J}$. Chem. Ecol. 18:571-583.

Feys, B., Benedetti, C. E., Penfold, C. N., and Turner, J. G. 1994. Arabidopsis mutants selected for resistance to the phytotoxin coronatine are male sterile, insensitive to methyl jasmonate, and resistant to a bacterial pathogen. Plant Cell 6:751-759.

Fowler, J. H., Narvaez-Vasquez, J., Aromdee, D. N., Pautot, V., Holzer, F M., and Walling, L. L. 2009. Leucine aminopeptidase regulates defense and wound signaling in tomato downstream of jasmonic acid. Plant Cell 21:1239-1251.

Gatehouse, J. A. 2011. Prospects for using proteinase inhibitors to protect transgenic plants against attack by herbivorous insects. Curr. Protein Pept. Sc. 12:409-416.

Gentleman, R. C., Carey, V. J., Bates, D. M., Bolstad, B., Dettling, M., Dudoit, S., Ellis, B., Gautier, L., Ge, Y., Gentry, J., Hornik, K., Hothorn, T., Huber, W., Iacus, S., Irizarry, R., Leisch, F., Li, C., Maechler, M., Rossini, A. J., Sawitzki, G., Smith, C., Smyth, G., Tierney, L., Yang, J. Y., and Zhang, J. 2004. Bioconductor: Open software development for computational biology and bioinformatics. Genome Biol. 5:R80.

Glas, J. J., Schimmel, B. C., Alba, J. M., Escobar-Bravo, R., Schuurink, R.
C., and Kant, M. R. 2012. Plant glandular trichomes as targets for breeding or engineering of resistance to herbivores. Int. J. Mol. Sci. 13:1707717103.

Gonzales-Vigil, E., Bianchetti, C. M., Phillips, G. N., Jr., and Howe, G. A 2011. Adaptive evolution of threonine deaminase in plant defense against insect herbivores. Proc. Natl. Acac. Sci. U.S.A. 108:5897-5902.

Grbic, M., Khila, A., Lee, K. Z., Bjelica, A., Grbic, V., Whistlecraft, J., Verdon, L., Navajas, M., and Nagy, L. 2007. Mity model: Tetranychus urticae, a candidate for chelicerate model organism. BioEssays 29:489496.

Grbic, M., Van Leeuwen, T., Clark, R. M., Rombauts, S., Rouze, P., Grbic, V., Osborne, E. J., Dermauw, W., Ngoc, P. C., Ortego, F., HernandezCrespo, P., Diaz, I., Martinez, M., Navajas, M., Sucena, E., Magalhaes, S., Nagy, L., Pace, R. M., Djuranovic, S., Smagghe, G., Iga, M., Christiaens, O., Veenstra, J. A., Ewer, J., Villalobos, R. M., Hutter, J. L., Hudson, S. D., Velez, M., Yi, S. V., Zeng, J., Pires-daSilva, A., Roch, F., Cazaux, M., Navarro, M., Zhurov, V., Acevedo, G., Bjelica, A., Fawcett, J. A., Bonnet, E., Martens, C., Baele, G., Wissler, L., Sanchez-Rodriguez, A., Tirry, L., Blais, C., Demeestere, K., Henz, S. R., Gregory, T. R., Mathieu, J., Verdon, L., Farinelli, L., Schmutz, J., Lindquist, E., Feyereisen, R., and Van de Peer, Y. 2011. The genome of Tetranychus urticae reveals herbivorous pest adaptations. Nature 479:487-492.

Green, T. R., and Ryan, C. A. 1972. Wound-induced proteinase inhibitor in plant leaves-Possible defense mechanism against insects. Science 175:776-777.

Gu, Y. Q., Holzer, F. M., and Walling, L. L. 1999. Overexpression, purification and biochemical characterization of the wound-induced leucine aminopeptidase of tomato. Eur. J. Biochem. 263:726-735.

Gu, Y. Q., Wildermuth, M. C., Chakravarthy, S., Loh, Y. T., Yang, C. M., He, X. H., Han, Y., and Martin, G. B. 2002. Tomato transcription factors Pti4, Pti5, and Pti6 activate defense responses when expressed in Arabidopsis. Plant Cell 14:817-831.

Guindon, S., Dufayard, J. F., Lefort, V., Anisimova, M., Hordijk, W., and Gascuel, O. 2010. New algorithms and methods to estimate maximumlikelihood phylogenies: Assessing the performance of PhyML 3.0. Syst. Biol. 59:307-321.

Heitz, T., Bergey, D. R., and Ryan, C. A. 1997. A gene encoding a chloroplast-targeted lipoxygenase in tomato leaves is transiently induced by wounding, systemin, and methyl jasmonate. Plant Physiol. 114:10851093.

Howe, G. A., and Jander, G. 2008. Plant immunity to insect herbivores. Annu. Rev. Plant Biol. 59:41-66.

Howe, G. A., Lightner, J., Browse, J., and Ryan, C. A. 1996. An octadecanoid pathway mutant (JL5) of tomato is compromised in signaling for defense against insect attack. Plant Cell 8:2067-2077.

Howe, G. A., Lee, G. I., Itoh, A., Li, L., and DeRocher, A. E. 2000. Cytochrome P450-dependent metabolism of oxylipins in tomato. Cloning and expression of allene oxide synthase and fatty acid hydroperoxide lyase. Plant Physiol. 123:711-724.

Huang, Z., Zhang, Z., Zhang, X., Zhang, H., Huang, D., and Huang, R. 2004. Tomato TERF1 modulates ethylene response and enhances osmotic stress tolerance by activating expression of downstream genes. FEBS (Fed. Eur. Biochem. Soc.) Lett. 573:110-116.

Hunter, S., Jones, P., Mitchell, A., Apweiler, R., Attwood, T. K., Bateman, A., Bernard, T., Binns, D., Bork, P., Burge, S., de Castro, E., Coggill, P. Corbett, M., Das, U., Daugherty, L., Duquenne, L., Finn, R. D., Fraser, M., Gough, J., Haft, D., Hulo, N., Kahn, D., Kelly, E., Letunic, I., Lonsdale, D., Lopez, R., Madera, M., Maslen, J., McAnulla, C., McDowall, J., McMenamin, C., Mi, H. Y., Mutowo-Muellenet, P., Mulder, N., Natale, D., Orengo, C., Pesseat, S., Punta, M., Quinn, A. F., Rivoire, C., Sangrador-Vegas, A., Selengut, J. D., Sigrist, C. J. A., Scheremetjew, M., Tate, J., Thimmajanarthanan, M., Thomas, P. D., Wu, C. H., Yeats, C., and Yong, S. Y. 2012. InterPro in 2011: New developments in the family and domain prediction database. Nucleic Acids Res 40:D306-D312.

Huson, D. H., Richter, D. C., Rausch, C., Dezulian, T., Franz, M., and Rupp, R. 2007. Dendroscope: An interactive viewer for large phylogenetic trees. BMC Bioinformatics 8:460. Published online.

Irizarry, R. A., Hobbs, B., Collin, F., Beazer-Barclay, Y. D., Antonellis, K. J., Scherf, U., and Speed, T. P. 2003. Exploration, normalization, and summaries of high density oligonucleotide array probe level data. Biostatistics 4:249-264.

Ishiga, Y., Ishiga, T., Uppalapati, S. R., and Mysore, K. S. 2013. Jasmonate ZIM-domain (JAZ) protein regulates host and nonhost pathogeninduced cell death in tomato and Nicotiana benthamiana. PloS One 8:e75728. Published online.

Itoh, A., Schilmiller, A. L., McCaig, B. C., and Howe, G. A. 2002. Identification of a jasmonate-regulated allene oxide synthase that metabolizes 9-hydroperoxides of linoleic and linolenic acids. J. Biol. Chem. 277:46051-46058 
Jeppson, L. R., Keifer, H. H., and Baker, E. W. 1975. Mites injurious to economic plants. University of California Press, Berkeley, CA, U.S.A.

Jones, P., Binns, D., Chang, H. Y., Fraser, M., Li, W., McAnulla, C., McWilliam, H., Maslen, J., Mitchell, A., Nuka, G., Pesseat, S., Quinn, A. F., Sangrador-Vegas, A., Scheremetjew, M., Yong, S. Y., Lopez, R., and Hunter, S. 2014. InterProScan 5: Genome-scale protein function classification. Bioinformatics 30:1236-1240.

Kant, M. R., Ament, K., Sabelis, M. W., Haring, M. A., and Schuurink, R. C. 2004. Differential timing of spider mite-induced direct and indirect defenses in tomato plants. Plant Physiol. 135:483-495.

Kant, M. R., Sabelis, M. W., Haring, M. A., and Schuurink, R. C. 2008. Intraspecific variation in a generalist herbivore accounts for differential induction and impact of host plant defences. P. Roy. Soc. Lond. B bio. 275:443-452.

Kauffmann, A., Gentleman, R., and Huber, W. 2009. arrayQualityMetrics-a bioconductor package for quality assessment of microarray data. Bioinformatics 25:415-416

Kazan, K., and Manners, J. M. 2013. MYC2: The master in action. Mol. Plant 6:686-703.

Kessler, A., and Baldwin, I. T. 2002. Plant responses to insect herbivory: The emerging molecular analysis. Annu. Rev. Plant Biol. 53:299-328.

Khila, A., and Grbic, M. 2007. Gene silencing in the spider mite Tetranychus urticae: dsRNA and siRNA parental silencing of the Distalless gene. Dev. Genes Evol. 217:241-251.

Kim, S. Y., and Volsky, D. J. 2005. PAGE: Parametric analysis of gene set enrichment. BMC Bioinformatics 6:144.

Kroymann, J. 2011. Natural diversity and adaptation in plant secondary metabolism. Curr. Opin. Plant Biol. 14:246-251.

Kuzuyama, T. 2002. Mevalonate and nonmevalonate pathways for the biosynthesis of isoprene units. Biosci. Biotech. Bioch. 66:1619-1627.

Le, S. Q., and Gascuel, O. 2008. An improved general amino acid replacement matrix. Mol. Biol. Evol. 25:1307-1320.

Li, C., Williams, M. M., Loh, Y. T., Lee, G. I., and Howe, G. A. 2002a. Resistance of cultivated tomato to cell content-feeding herbivores is regulated by the octadecanoid-signaling pathway. Plant Physiol. 130:494503

Li, C. Y., Williams, M. M., Loh, Y. T., Lee, G. I., and Howe, G. A. 2002b. Resistance of cultivated tomato to cell content-feeding herbivores is regulated by the octadecanoid-signaling pathway. Plant Physiol. 130:494-503.

Li, L., Zhao, Y., McCaig, B. C., Wingerd, B. A., Wang, J., Whalon, M. E., Pichersky, E., and Howe, G. A. 2004. The tomato homolog of CORONATINE-INSENSITIVE1 is required for the maternal control of seed maturation, jasmonate-signaled defense responses, and glandular trichome development. Plant Cell 16:126-143.

Liebrand, T. W., van den Berg, G. C., Zhang, Z., Smit, P., Cordewener, J. H., America, A. H., Sklenar, J., Jones, A. M., Tameling, W. I., Robatzek, S., Thomma, B. P., and Joosten, M. H. 2013. Receptor-like kinase SOBIR1/EVR interacts with receptor-like proteins in plant immunity against fungal infection. Proc. Natl. Acac. Sci. U.S.A. 110:1001010015.

Liebrand, T. W. H., van den Burg, H. A., and Joosten, M. H. A. J. 2014 Two for all: Receptor-associated kinases SOBIR1 and BAK1. Trends Plant Sci. 19:123-132.

Lincoln, J. E., Campbell, A. D., Oetiker, J., Rottmann, W. H., Oeller, P. W., Shen, N. F., and Theologis, A. 1993. LE-ACS4, a fruit ripening and wound-induced 1-aminocyclopropane-1-carboxylate synthase gene of tomato (Lycopersicon esculentum). Expression in Escherichia coli, structural characterization, expression characteristics, and phylogenetic analysis. J. Biol. Chem. 268:19422-19430.

Merchante, C., Alonso, J. M., and Stepanova, A. N. 2013. Ethylene signaling: Simple ligand, complex regulation. Curr. Opin. Plant Biol. 16:554560

Mi, H. Y., Lazareva-Ulitsky, B., Loo, R., Kejariwal, A., Vandergriff, J., Rabkin, S., Guo, N., Muruganujan, A., Doremieux, O., Campbell, M. J., Kitano, H., and Thomas, P. D. 2005. The PANTHER database of protein families, subfamilies, functions and pathways. Nucleic Acids Res. 33:D284-D288.

Migeon, A., and Dorkeld, F. 2006-2014. Spider mites web: A comprehensive database for the Tetranychidae. Institute for Agronomy ResearchThe Center for Biology and Management of Populations, Montpellier, France. www.montpellier.inra.fr/CBGP/spmweb. Published online.

Mirnezhad, M., Romero-Gonzalez, R. R., Leiss, K. A., Choi, Y. H., Verpoorte, R., and Klinkhamer, P. G. L. 2010. Metabolomic analysis of host plant resistance to thrips in wild and cultivated tomatoes. Phytochem. Analysis 21:110-117.

Mithofer, A., and Boland, W. 2012. Plant defense against herbivores: Chemical aspects. Annu. Rev. Plant Biol. 63:431-450.

Musser, R. O., Hum-Musser, S. M., Eichenseer, H., Peiffer, M., Ervin, G., Murphy, J. B., and Felton, G. W. 2002. Herbivory: Caterpillar saliva beats plant defences. Nature 416:599-600.

Mutschler, M. A., Doerge, R. W., Liu, S. C., Kuai, J. P., Liedl, B. E., and Shapiro, J. A. 1996. QTL analysis of pest resistance in the wild tomato Lycopersicon pennellii: QTLs controlling acylsugar level and composition. Theor. Appl. Genet. 92:709-718.

Myhre, S., Tveit, H., Mollestad, T., and Laegreid, A. 2006. Additional Gene Ontology structure for improved biological reasoning. Bioinformatics 22:2020-2027.

Nachappa, P., Margolies, D. C., Nechols, J. R., Whitfield, A. E., and Rotenberg, D. 2013. Tomato spotted wilt virus benefits a non-vector arthropod, Tetranychus urticae, by modulating different plant responses in tomato. PloS One 8:e75909. Published online.

Nakatsuka, A., Murachi, S., Okunishi, H., Shiomi, S., Nakano, R., Kubo, Y., and Inaba, A. 1998. Differential expression and internal feedback regulation of 1-aminocyclopropane-1-carboxylate synthase, 1-aminocyclopropane-1-carboxylate oxidase, and ethylene receptor genes in tomato fruit during development and ripening. Plant Physiol. 118:12951305 .

Nguyen, N. N. T., Ranwez, V., Vile, D., Soulie, M. C., Dellagi, A., Expert, D., and Gosti, F. 2014. Evolutionary tinkering of the expression of PDF1s suggests their joint effect on zinc tolerance and the response to pathogen attack. Front. Plant Sci. 5. Published online.

Ober, D. 2010. Gene duplications and the time thereafter-Examples from plant secondary metabolism. Plant Biol. (Stuttg) 12:570-577.

Oetiker, J. H., Olson, D. C., Shiu, O. Y., and Yang, S. F. 1997. Differential induction of seven 1-aminocyclopropane-1-carboxylate synthase genes by elicitor in suspension cultures of tomato (Lycopersicon esculentum) Plant Mol. Biol. 34:275-286.

Olson, D. C., Oetiker, J. H., and Yang, S. F. 1995. Analysis of LE-ACS3, a 1-aminocyclopropane-1-carboxylic acid synthase gene expressed during flooding in the roots of tomato plants. J. Biol. Chem. 270:1405614061 .

Ortego, F. 2012. Physiological adaptations of the insect gut to herbivory. Pages 75-88 in: Arthropod-Plant Interactions, G. Smagghe and I. Diaz, eds. Springer Netherlands, Heidelberg, Germany.

Overbeek, R., Fonstein, M., D’Souza, M., Pusch, G. D., and Maltsev, N. 1999. The use of gene clusters to infer functional coupling. Proc. Natl Acac. Sci. U.S.A. 96:2896-2901.

Penninckx, I. A., Eggermont, K., Terras, F. R., Thomma, B. P., De Samblanx, G. W., Buchala, A., Metraux, J. P., Manners, J. M., and Broekaert, W. F. 1996. Pathogen-induced systemic activation of a plant defensin gene in Arabidopsis follows a salicylic acid-independent pathway. Plant Cell 8:2309-2323.

Pirrello, J., Jaimes-Miranda, F., Sanchez-Ballesta, M. T., Tournier, B., Khalil-Ahmad, Q., Regad, F., Latche, A., Pech, J. C., and Bouzayen, M. 2006. Sl-ERF2, a tomato ethylene response factor involved in ethylene response and seed germination. Plant Cell Physiol. 47:1195-1205.

Postel, S., Kufner, I., Beuter, C., Mazzotta, S., Schwedt, A., Borlotti, A. Halter, T., Kemmerling, B., and Nurnberger, T. 2010. The multifunctional leucine-rich repeat receptor kinase BAK1 is implicated in Arabidopsis development and immunity. Eur. J. Cell Biol. 89:169-174.

Ramsak, Z., Baebler, S., Rotter, A., Korbar, M., Mozetic, I., Usadel, B., and Gruden, K. 2014. GoMapMan: Integration, consolidation and visualization of plant gene annotations within the MapMan ontology. Nucleic Acids Res. 42:D1167-1175.

Rawlings, N. D., Waller, M., Barrett, A. J., and Bateman, A. 2014 MEROPS: The database of proteolytic enzymes, their substrates and inhibitors. Nucleic Acids Res. 42:D503-509.

Resende, J. T., Maluf, W. R., Cardoso, M., Nelson, D. L., and Faria, M. V. 2002. Inheritance of acylsugar contents in tomatoes derived from an interspecific cross with the wild tomato Lycopersicon pennellii and their effect on spider mite repellence. Genet. Mol. Res. 1:106-116.

Rieu, I., and Powers, S. J. 2009. Real-time quantitative RT-PCR: Design, calculations, and statistics. Plant Cell 21:1031-1033.

Rottmann, W. H., Peter, G. F., Oeller, P. W., Keller, J. A., Shen, N. F., Nagy, B. P., Taylor, L. P., Campbell, A. D., and Theologis, A. 1991. 1aminocyclopropane-1-carboxylate synthase in tomato is encoded by a multigene family whose transcription is induced during fruit and floral senescence. J. Mol. Biol. 222:937-961

Salinas, M., Capel, C., Alba, J. M., Mora, B., Cuartero, J., FernandezMunoz, R., Lozano, R., and Capel, J. 2013. Genetic mapping of two QTL from the wild tomato Solanum pimpinellifolium L. controlling resistance against two-spotted spider mite (Tetranychus urticae Koch). TAG. Theor. Appl. Genet. 126:83-92.

Santamaria, M. E., Cambra, I., Martinez, M., Pozancos, C., GonzalezMelendi, P., Grbic, V., Castanera, P., Ortego, F., and Diaz, I. 2012. Gene pyramiding of peptidase inhibitors enhances plant resistance to the spider mite Tetranychus urticae. PloS one 7:e43011. Published online.

Santamaria, M. E., Martinez, M., Cambra, I., Grbic, V., and Diaz, I. 2013. Understanding plant defence responses against herbivore attacks: An 
essential first step towards the development of sustainable resistance against pests. Transgenic Res. 22:697-708

Sarmento, R. A., Lemos, F., Bleeker, P. M., Schuurink, R. C., Pallini, A., Oliveira, M. G., Lima, E. R., Kant, M., Sabelis, M. W., and Janssen, A. 2011. A herbivore that manipulates plant defence. Ecol. Lett. 14:229-236.

Sato, S., Tabata, S., Hirakawa, H., Asamizu, E., Shirasawa, K., Isobe, S., Kaneko, T., Nakamura, Y., Shibata, D., Aoki, K., Egholm, M., Knight, J., Bogden, R., Li, C. B., Shuang, Y., Xu, X., Pan, S. K., Cheng, S. F., Liu, X., Ren, Y. Y., Wang, J., Albiero, A., Dal Pero, F., Todesco, S., Van Eck, J., Buels, R. M., Bombarely, A., Gosselin, J. R., Huang, M. Y., Leto, J. A., Menda, N., Strickler, S., Mao, L. Y., Gao, S., Tecle, I. Y. York, T., Zheng, Y., Vrebalov, J. T., Lee, J., Zhong, S. L., Mueller, L. A., Stiekema, W. J., Ribeca, P., Alioto, T., Yang, W. C., Huang, S. W., Du, Y. C., Zhang, Z. H., Gao, J. C., Guo, Y. M., Wang, X. X., Li, Y., He, J., Li, C. Y., Cheng, Z. K., Zuo, J. R., Ren, J. F., Zhao, J. H., Yan, L. H., Jiang, H. L., Wang, B., Li, H. S., Li, Z. J., Fu, F. Y., Chen, B. T., Han, B., Feng, Q., Fan, D. L., Wang, Y., Ling, H. Q., Xue, Y. B. A., Ware, D., McCombie, W. R., Lippman, Z. B., Chia, J. M., Jiang, K., Pasternak, S., Gelley, L., Kramer, M., Anderson, L. K., Chang, S. B., Royer, S. M., Shearer, L. A., Stack, S. M., Rose, J. K. C., Xu, Y. M., Eannetta, N., Matas, A. J., McQuinn, R., Tanksley, S. D., Camara, F., Guigo, R., Rombauts, S., Fawcett, J., Van de Peer, Y., Zamir, D., Liang, C. B., Spannagl, M., Gundlach, H., Bruggmann, R., Mayer, K., Jia, Z. Q., Zhang, J. H., Ye, Z. B. A., Bishop, G. J., Butcher, S., Lopez-Cobollo, R., Buchan, D., Filippis, I., Abbott, J., Dixit, R., Singh, M., Singh, A., Pal, J. K., Pandit, A., Singh, P. K., Mahato, A. K., Dogra, V., Gaikwad, K., Sharma, T. R., Mohapatra, T., Singh, N. K., Causse, M., Rothan, C., Schiex, T., Noirot, C., Bellec, A., Klopp, C., Delalande, C., Berges, H., Mariette, J., Frasse, P., Vautrin, S., Zouine, M., Latche, A., Rousseau, C., Regad, F., Pech, J. C., Philippot, M., Bouzayen, M., Pericard, P., Osorio, S., del Carmen, A. F., Monforte, A., Granell, A., FernandezMunoz, R., Conte, M., Lichtenstein, G., Carrari, F., De Bellis, G., Fuligni, F., Peano, C., Grandillo, S., Termolino, P., Pietrella, M., Fantini, E., Falcone, G., Fiore, A., Giuliano, G., Lopez, L., Facella, P., Perrotta, G., Daddiego, L., Bryan, G., Orozco, M., Pastor, X., Torrents, D., van Schriek, K. N. V. M. G. M., Feron, R. M. C., van Oeveren, J., de Heer, P., daPonte, L., Jacobs-Oomen, S., Cariaso, M., Prins, M., van Eijk, M. J. T., Janssen, A., van Haaren, M. J. J., Jo, S. H., Kim, J., Kwon, S. Y., Kim, S., Koo, D. H., Lee, S., Hur, C. G., Clouser, C., Rico, A., Hallab, A., Gebhardt, C., Klee, K., Jocker, A., Warfsmann, J., Gobel, U., Kawamura, S., Yano, K., Sherman, J. D., Fukuoka, H., Negoro, S., Bhutty, S., Chowdhury, P., Chattopadhyay, D., Datema, E., Smit, S., Schijlen, E. W. M., van de Belt, J., van Haarst, J. C., Peters, S. A., van Staveren, M. J., Henkens, M. H. C., Mooyman, P. J. W., Hesselink, T., van Ham, R. C. H. J., Jiang, G. Y., Droege, M., Choi, D., Kang, B. C. Kim, B. D., Park, M., Kim, S., Yeom, S. I., Lee, Y. H., Choi, Y. D., Li, G. C., Gao, J. W., Liu, Y. S., Huang, S. X., Fernandez-Pedrosa, V., Collado, C., Zuniga, S., Wang, G. P., Cade, R., Dietrich, R. A., Rogers, J., Knapp, S., Fei, Z. J., White, R. A., Thannhauser, T. W., Giovannoni, J. J., Botella, M. A., Gilbert, L., Gonzalez, R., Goicoechea, J. L., Yu, Y., Kudrna, D., Collura, K., Wissotski, M., Wing, R., Schoof, H., Meyers, B. C., Gurazada, A. B., Green, P. J., Mathur, S., Vyas, S., Solanke, A. U., Kumar, R., Gupta, V., Sharma, A. K., Khurana, P., Khurana, J. P., Tyagi, A. K., Dalmay, T., Mohorianu, I., Walts, B., Chamala, S., Barbazuk, W. B., Li, J. P., Guo, H., Lee, T. H., Wang, Y. P., Zhang, D., Paterson, A. H., Wang, X. Y., Tang, H. B., Barone, A., Chiusano, M. L., Ercolano, M. R., D’Agostino, N., Di Filippo, M., Traini, A., Sanseverino, W., Frusciante, L., Seymour, G. B., Elharam, M., Fu, Y., Hua, A., Kenton, S., Lewis, J., Lin, S. P., Najar, F., Lai, H. S., Qin, B. F., Qu, C.M., Shi, R. H., White, D., White, J., Xing, Y. B., Yang, K. Q., Yi, J., Yao, Z. Y., Zhou, L. P., Roe, B. A., Vezzi, A., D’Angelo, M., Zimbello, R., Schiavon, R., Caniato, E., Rigobello, C., Campagna, D., Vitulo, N., Valle, G., Nelson, D. R., De Paoli, E., Szinay, D., de Jong, H. H., Bai, Y. L., Visser, R. G. F., Lankhorst, R. M. K., Beasley, H., McLaren, K., Nicholson, C., Riddle, C., Gianese, G., and Consortium, T. G. 2012. The tomato genome sequence provides insights into fleshy fruit evolution. Nature 485:635-641.

Schluter, U., Benchabane, M., Munger, A., Kiggundu, A., Vorster, J., Goulet, M. C., Cloutier, C., and Michaud, D. 2010. Recombinant protease inhibitors for herbivore pest control: A multitrophic perspective. J. Exp. Bot. 61:4169-4183.

Schwachtje, J., and Baldwin, I. T. 2008. Why does herbivore attack reconfigure primary metabolism? Plant Physiol. 146:845-851.

Schweighofer, A., Kazanaviciute, V., Scheikl, E., Teige, M., Doczi, R., Hirt, H., Schwanninger, M., Kant, M., Schuurink, R., Mauch, F., Buchala, A., Cardinale, F., and Meskiene, I. 2007. The PP2C-type phosphatase AP2C1, which negatively regulates MPK4 and MPK6, modulates innate immunity, jasmonic acid, and ethylene levels in Arabidopsis. Plant Cell 19:2213-2224.

Sell, S., and Hehl, R. 2005. A fifth member of the tomato 1-aminocyclopropane-1-carboxylic acid (ACC) oxidase gene family harbours a leucine zipper and is anaerobically induced. DNA Sequence 16:80-82.

Sheard, L. B., Tan, X., Mao, H., Withers, J., Ben-Nissan, G., Hinds, T. R., Kobayashi, Y., Hsu, F. F., Sharon, M., Browse, J., He, S. Y., Rizo, J., Howe, G. A., and Zheng, N. 2010. Jasmonate perception by inositolphosphate-potentiated COI1-JAZ co-receptor. Nature 468:400-405.

Shiu, O. Y., Oetiker, J. H., Yip, W. K., and Yang, S. F. 1998. The promoter of LE-ACS7, an early flooding-induced 1-aminocyclopropane-1-carboxylate synthase gene of the tomato, is tagged by a Sol3 transposon. Proc. Natl. Acac. Sci. U.S.A. 95:10334-10339.

Silva, P. M., Goncalves, S., and Santos, N. C. 2014. Defensins: Antifungal lessons from eukaryotes. Frontiers in microbiology 5:97.

Silverstein, K. A., Graham, M. A., Paape, T. D., and VandenBosch, K. A. 2005. Genome organization of more than 300 defensin-like genes in Arabidopsis. Plant Physiol. 138:600-610.

Silverstein, K. A., Moskal, W. A., Jr., Wu, H. C., Underwood, B. A., Graham, M. A., Town, C. D., and VandenBosch, K. A. 2007. Small cysteine-rich peptides resembling antimicrobial peptides have been under-predicted in plants. Plant J. 51:262-280.

Smyth, G. K. 2004. Linear models and empirical bayes methods for assessing differential expression in microarray experiments. Stat. Appl. Genet. Mol. Biol. 3:Article3. Published online.

Steppuhn, A., Schuman, M. C., and Baldwin, I. T. 2008. Silencing jasmonate signalling and jasmonate-mediated defences reveals different survival strategies between two Nicotiana attenuata accessions. Mol Ecol. 17:3717-3732.

Strassner, J., Schaller, F., Frick, U. B., Howe, G. A., Weiler, E. W., Amrhein, N., Macheroux, P., and Schaller, A. 2002. Characterization and cDNA microarray expression analysis of 12-oxophytodienoate reductases reveals differential roles for octadecanoid biosynthesis in the local versus the systemic wound response. Plant J. 32:585-601.

Thaler, J. S., Fidantsef, A. L., and Bostock, R. M. 2002. Antagonism between jasmonate- and salicylate-mediated induced plant resistance: Effects of concentration and timing of elicitation on defense-related proteins, herbivore, and pathogen performance in tomato. J. Chem. Ecol. 28:1131-1159.

Thaler, J. S., Agrawal, A. A., and Halitschke, R. 2010. Salicylate-mediated interactions between pathogens and herbivores. Ecology 91:1075-1082.

Thaler, J. S., Humphrey, P. T., and Whiteman, N. K. 2012. Evolution of jasmonate and salicylate signal crosstalk. Trends Plant Sci. 17:260-270.

Thines, B., Katsir, L., Melotto, M., Niu, Y., Mandaokar, A., Liu, G., Nomura, K., He, S. Y., Howe, G. A., and Browse, J. 2007. JAZ repressor proteins are targets of the $\mathrm{SCF}(\mathrm{COI} 1)$ complex during jasmonate signalling. Nature 448:661-665.

Tournier, B., Sanchez-Ballesta, M. T., Jones, B., Pesquet, E., Regad, F., Latche, A., Pech, J. C., and Bouzayen, M. 2003. New members of the tomato ERF family show specific expression pattern and diverse DNAbinding capacity to the GCC box element. FEBS (Fed. Eur. Biochem. Soc.) Lett. 550:149-154.

Tran, L. T., Taylor, J. S., and Constabel, C. P. 2012. The polyphenol oxidase gene family in land plants: Lineage-specific duplication and expansion. BMC Genomics 13:395.

Uehara, T., Sugiyama, S., Matsuura, H., Arie, T., and Masuta, C. 2010. Resistant and susceptible responses in tomato to cyst nematode are differentially regulated by salicylic acid. Plant Cell Physiol. 51:1524-1536.

Van Leeuwen, T., Demaeght, P., Osborne, E. J., Dermauw, W., Gohlke, S Nauen, R., Grbić, M., Tirry, L., Merzendorfer, H., and Clark, R. M. 2012. Population bulk segregant mapping uncovers resistance mutations and the mode of action of a chitin synthesis inhibitor in arthropods. Proc. Natl. Acad. Sci. U.S.A. 109:4407-4412.

Van Leeuwen, T., Dermauw, W., Grbic, M., Tirry, L., and Feyereisen, R. 2013. Spider mite control and resistance management: Does a genome help? Pest Manag. Sci. 69:156-159.

Varemo, L., Nielsen, J., and Nookaew, I. 2013. Enriching the gene set analysis of genome-wide data by incorporating directionality of gene expression and combining statistical hypotheses and methods. Nucleic Acids Res. 41:4378-4391

Wan, J. R., Tanaka, K., Zhang, X. C., Son, G. H., Brechenmacher, L., Tran, H. N. N., and Stacey, G. 2012. LYK4, a lysin motif receptor-like kinase, is important for chitin signaling and plant innate immunity in Arabidopsis. Plant Physiol. 160:396-406.

Wang, H., Huang, Z., Chen, Q., Zhang, Z., Zhang, H., Wu, Y., Huang, D., and Huang, R. 2004. Ectopic overexpression of tomato JERF3 in tobacco activates downstream gene expression and enhances salt tolerance. Plant Mol. Biol. 55:183-192.

Xie, D. X., Feys, B. F., James, S., Nieto-Rostro, M., and Turner, J. G. 1998. COI1: An Arabidopsis gene required for jasmonate-regulated defense and fertility. Science 280:1091-1094.

Yamaguchi, Y., and Huffaker, A. 2011. Endogenous peptide elicitors in higher plants. Curr. Opin. Plant Biol. 14:351-357.

Yan, L., Zhai, Q., Wei, J., Li, S., Wang, B., Huang, T., Du, M., Sun, J., 
Kang, L., Li, C. B., and Li, C. 2013. Role of tomato lipoxygenase D in wound-induced jasmonate biosynthesis and plant immunity to insect herbivores. PLoS Genet. 9:e1003964. Published online.

Yip, W. K., Moore, T., and Yang, S. F. 1992. Differential accumulation of transcripts for four tomato 1-aminocyclopropane-1-carboxylate synthase homologs under various conditions. Proc. Natl. Acac. Sci. U.S.A. 89:2475-2479.

Zhang, H., Huang, Z., Xie, B., Chen, Q., Tian, X., Zhang, X., Zhang, H., Lu, X., Huang, D., and Huang, R. 2004. The ethylene-, jasmonate-, abscisic acid- and $\mathrm{NaCl}$-responsive tomato transcription factor JERF1 modulates expression of GCC box-containing genes and salt tolerance in tobacco. Planta 220:262-270.

Zhang, H., Yang, Y., Zhang, Z., Chen, J., Wang, X. C., and Huang, R. 2008. Expression of the ethylene response factor gene TSRF1 enhances abscisic acid responses during seedling development in tobacco. Planta 228:777-787.

Zhang, P. J., Zheng, S. J., van Loon, J. J. A., Boland, W., David, A., Mumm, R., and Dicke, M. 2009. Whiteflies interfere with indirect plant defense against spider mites in lima bean. Proc. Natl. Acac. Sci. U.S.A. 106:21202-21207.

Zhang, Z.-Q. 2003. Mites of greenhouses: Identification, biology and control. CABI Pub., Wallingford, Oxon, U.K.
Zhang, Z., Zhang, H., Quan, R., Wang, X. C., and Huang, R. 2009. Transcriptional regulation of the ethylene response factor LeERF2 in the expression of ethylene biosynthesis genes controls ethylene production in tomato and tobacco. Plant Physiol. 150:365-377.

Zheng, S.-J., van Dijk, J. P., Bruinsma, M., and Dicke, M. 2007. Sensitivity and speed of induced defense of cabbage (Brassica oleracea L.): Dynamics of BoLOX expression patterns during insect and pathogen attack. Mol. Plant-Microbe Interact. 20:1332-1345.

Zhou, J., Tang, X., and Martin, G. B. 1997. The Pto kinase conferring resistance to tomato bacterial speck disease interacts with proteins that bind a cis-element of pathogenesis-related genes. EMBO (Eur. Mol. Biol. Organ.) J. 16:3207-3218.

Zhu-Salzman, K., Luthe, D. S., and Felton, G. W. 2008. Arthropod-inducible proteins: Broad spectrum defenses against multiple herbivores. Plant Physiol. 146:852-858.

Zhurov, V., Navarro, M., Bruinsma, K. A., Arbona, V., Santamaria, M. E., Cazaux, M., Wybouw, N., Osborne, E. J., Ens, C., Rioja, C., Vermeirssen, V., Rubio-Somoza, I., Krishna, P., Diaz, I., Schmid, M., GomezCadenas, A., Van de Peer, Y., Grbic, M., Clark, R. M., Van Leeuwen, T., and Grbic, V. 2014. Reciprocal responses in the interaction between Arabidopsis and the cell-content-feeding chelicerate herbivore spider mite. Plant Physiol. 164:384-399. 